\title{
JUNTA, REGENCIA Y REPRESENTACIÓN. LA ELECCIÓN DE LOS SUPLENTES AMERICANOS A LAS PRIMERAS CORTES'
}

\author{
Ivana Frasquet \\ Universitat Jaume I - Castellón
}

\section{Resumo}

Este artigo aborda a eleição dos deputados americanos para as Cortes de Cádiz em 1810. O contexto revolucionário da Junta Central e a criação do Estado liberal é seu tema principal. A importância da representação da América não está no número de deputados mas no fato em si mesmo: esta foi a primeira vez na história da Monarquia espanhola em que as colônias tiveram um lugar nas novas instituições liberais criadas.

\section{Pallavras-chaves}

Deputados americanos • representação • Cortes de Cádiz

\section{Abstract}

This article discusses the election of the American representatives to the Cortes de Cádiz in 1810. The Revolutionary context of the Junta Central and the creation of the liberal State are the main topics approached. The importance of this election is not about the number of the representatives, it's concerned with the principle of their representation. It was the first time in the history of the Monarchy that the colonies had a place in the new liberal institutions.

\section{Keywords}

American representatives • representation • Cortes de Cádiz.

\footnotetext{
${ }^{1}$ Esta investigación se ha realizado con la ayuda de los proyectos financiados por la Fundación Carolina (FC/06) y el Ministerio de Educación y Ciencia (HUM2006-09581)
} 


\section{La Junta Central y la convocatoria}

25 de septiembre de 1808. Se reúne la Junta Central. La secuencia de acontecimientos ocurrida anteriormente es conocida. Abdicación de Carlos IV en su hijo Fernando, salida de la familia real hacia Francia, levantamiento del pueblo madrileño el dos de mayo, formación de juntas provinciales, abdicaciones de Bayona y nombramiento del nuevo rey en la persona de José Bonaparte 2 .

Durante la primera quincena de septiembre de 1808 fueron llegando a Madrid los diputados elegidos en las provincias para componer la Junta Central. La instalación de la Junta Central se verificó el 25 de septiembre de 1808 a las 9:30h de la mañana en el Palacio del Real Sitio de Aranjuez. Los vocales oyeron misa en la capilla y juraron conservar y aumentar la religión católica, defender a Fernando VII, sus derechos y soberanía y conservar los fueros, leyes y costumbres, especialmente los de sucesión de la familia reinante ${ }^{3}$. El presidente interino, el conde de Floridablanca, que posteriormente sería reelegido para ocupar el puesto, declaró legítimamente constituida la Junta, a pesar de que se encontraban presentes dos tercios del total de sus miembros. E, inmediatamente, se circuló a todas las autoridades del reino la noticia de la instalación con la orden de prestar el juramento debido a la Junta. La resistencia más tenaz al cumplimiento de las órdenes emanadas de la Junta provino casi

\footnotetext{
${ }^{2}$ La bibliografía en torno a estos acontecimientos es abundante. Sin ánimo de ser exhaustiva, puede consultarse, ROURA, Lluís. Guerra y ocupación francesa. ¿freno o estímulo a la Revolución española?, In: CHUST, Manuel e FRASQUET, Ivana (eds.). La trascendencia del liberalismo doceañista en España y en América. Valencia: Biblioteca Valenciana, 2004, p. 13-30. AYMES, J. R.. La guerra de independencia en España (1808-1814). Madri: Siglo XXI, 1986. LOVETT, Gabriel H.. La guerra de la independencia y el nacimiento de la España contemporánea. Barcelona: Península, 2 v., 1975. ARTOLA, Miguel. Los orígenes de la España contemporánea. Madri: Instituto de Estudios Políticos, 2 v., 1975 y del mismo autor la reciente obra La guerra de independencia. Madri: Espasa, 2007. FONTANA, Josép. La crisis del Antiguo Régimen, 1808-1833. Barcelona: Ariel, 1971. LA PARRA, Emilio. Manuel Godoy. La aventura del poder.Barcelona: Ed. Tusquets, 2002. Sobre las juntas, MOLINER, Antonio. Revolución burguesa y movimiento juntero en España. LLEIDA, Milenio, 1997 e CHUST, Manuel (ed.), 1808. La eclosión juntera en el mundo hispano. México: FCE, 2007.

${ }^{3}$ Sobre los detalles de la formación de la Junta Central se puede consultar la obra de CASTEL, Jorge. La Junta Central Suprema y Gubernativa de España e Indias. Su creación, organización y funcionamiento. Madri: Marto, 1950. Esta obra ofrece los detalles sobre formación, composición y atribuciones de la Junta pero no sobre la actuación de la misma en el contexto de la guerra y la revolución. Los documentos originales están transcritos en FERNÁNDEZ MARTÍN, Manuel. Derecho parlamentario español. Madrid: Publicaciones del Congreso de los diputados, tomo 1, 1992.
} 
siempre del Consejo de Castilla, cuyos miembros se consideraban la autoridad primera del reino.

Nada más iniciarse los trabajos, la Junta estableció cinco comisiones correspondientes con los cinco ministerios existentes, a saber: Estado, Gracia y Justicia, Guerra, Marina y Hacienda. Más tarde, por decreto de 3 de noviembre de 1808, se crearía la Secretaría de Estado y General del Despacho de la Junta Central, cuyo objetivo era auxiliar y facilitar la labor de la Junta en los numerosos asuntos de que debía entender. Para ocupar el cargo se eligió al que era el secretario de la Junta, a Martín de Garay, quien lo desempeñó hasta el 9 de noviembre de 1809 .

En los debates que se dieron en la comisión acerca de la convocatoria de las Cortes, es conocido el voto que expidió en 7 de octubre de 1808 Gaspar Melchor de Jovellanos, vocal asturiano, sobre la formación de las Cortes y del gobierno. Éste reconocía la legitimidad con que se formaron las juntas provinciales y, por ende, la central y establecía la reunión de las Cortes para el 1 de octubre de 1810 y el nombramiento de un Consejo de Regencia para el 1 de enero de 1809. Este Consejo debería asumir toda la soberanía de la Junta, que tras su instalación, quedaría reducida a una mera junta de correspondencia y consulta con la mitad de sus vocales ${ }^{4}$. Sin embargo, el dictamen de Jovellanos no llegó a discutirse en el seno de la Junta, aún cuando se señalara para su debate el día 7 de noviembre.

Hacia finales de noviembre la Junta Central decidió trasladarse a posiciones más seguras. Napoleón había iniciado el ataque a lo largo de la ruta de Madrid y llegó a las puertas de la capital el 2 de diciembre. Ante la negativa de la rendición se producirán los primeros ataques desde las alturas del Retiro que obligarán a la capitulación dos días después ${ }^{5}$. El 1 de diciembre había salido la Junta de Aranjuez con destino a Toledo y luego Badajoz, sin embargo, en Trujillo se decide cambiar el rumbo y dirigirse a Sevilla. El día 16 llegaba la Junta a la ciudad de Sevilla, siendo recibida por un repique de campanas de la Giralda, el ayuntamiento y la junta suprema de Sevilla, quienes le ofrecieron

\footnotetext{
${ }^{4}$ El texto íntegro en FERNÁNDEZ MARTÍN, Manuel. Derecho parlamentario español. Madri: Publicaciones del Congreso de los diputados, tomo 1, 1992, p. 387-401.

${ }^{5}$ Los detalles de las fuerzas y las campañas de la guerra en ARTOLA, Miguel. La guerra de la independencia. Madri: Espasa, 2007. También puede consultarse el reciente libro de ESDAILE, Charles. España contra Napoleón. Guerrillas, bandoleros y el mito del pueblo en armas (18081814). Barcelona: Crítica, 2006.
} 
sus respetos. Sin embargo, la muerte del presidente de la Junta Central, el conde de Floridablanca, el 30 de diciembre de 1808, desestabilizó a la misma que tuvo que nombrar a su vicepresidente, el marqués de Astorga, para ocupar el cargo interinamente.

Hacia mediados de abril de 1809, el vocal Lorenzo Calvo de Rozas de Aragón, presentó una proposición en la que insistía en convocar las Cortes ${ }^{6}$. La discusión de la Junta sobre este tema dio como resultado un proyecto de decreto basado en la opinión de la mayoría favorable a la convocatoria de Cortes. Este proyecto solicitaba el envío de propuestas de reforma por parte de los ilustrados de la nación sobre distintos ramos de la administración pública, que luego pasarían a las comisiones para ser examinadas. También insistía, de forma explícita, en la necesidad de formar una Constitución y en unos principios irrenunciables de los que no debían separarse los que contribuyeran con sus escritos o debates a la discusión y que se manifestaban en el proyecto. Entre estos principios se encontraba la asunción de que "la nación ha de ser gobernada en adelante por leyes libremente deliberadas y admitidas"-lo que suponía cuestionar en su punto más importante el principio de soberanía real del Estado absoluto-o la mención explícita a la igualdad americana: "Nuestras Américas y demás colonias serán iguales a la Metrópoli en todos los derechos y prerrogativas constitucionales"”. Este principio insistía en el planteamiento del conocido decreto de 22 de enero de 1809 por el que los territorios americanos se consideraron parte integrante de la monarquía española y se les invitaba a elegir un representante a la Junta $\mathrm{Central}^{8}$. Es decir, si por primera vez, con la elección de americanos para la

\footnotetext{
${ }^{6}$ En realidad en su escrito, Calvo de Rozas proponía la reforma de la administración y de la Constitución, animando a todos aquellos que se sintieran con capacidad de aportar alguna idea a enviar a la secretaría de la Junta sus propuestas. Esta consulta dio lugar a los conocidos informes recabados por la Central que han sido estudiados entre otros, por ARRIAZU, Ma Isabel. La consulta de la Junta Central al país sobre Cortes. Pamplona: Universidad de Navarra. También algunos en ARTOLA, Miguel. Los orígenes de la España contemporánea. Madri: Instituto de Estudios Políticos, 1959.

${ }^{7}$ El proyecto íntegro, así como los dictámenes y votos particulares a los que dio lugar, en FERNÁNDEZ MARTÍN, Manuel. Derecho parlamentario español. Madri: Publicaciones del Congreso de los diputados, tomo 1, 1992, p. 439 y ss.

${ }^{8}$ Quien ha señalado el carácter altamente revolucionario de estos planteamientos ha sido CHUST, Manuel, La cuestión nacional americana en las Cortes de Cádiz, Valencia, Fundación Instituto Historia Social-unED-unAm, 1999. Aunque carecemos de un estudio detallado y minucioso de los representantes americanos elegidos para la Junta Central, conocemos los poderes que les fueron extendidos en sus territorios. Se puede seguir el relato de estas elecciones en algunos capítulos del reciente libro de CHUST, Manuel (ed.). 1808. La eclosión juntera en el mundo hispano, México,
} 
Junta, éstos participaban de un órgano de gobierno de la monarquía, ahora, por primera vez, iban a formar parte también de la representación nacional.

Fruto de la discusión de este proyecto fue el decreto sobre restablecimiento y convocatoria de Cortes expedido por la Junta Central el 22 de mayo de 1809. En él se establecía que las Cortes se convocarían a lo largo del año de 1810, se nombraba una comisión de cinco vocales para redactar esta convocatoria ${ }^{9}$ y se estipulaba una serie de puntos sobre los que la Junta Central debía proponer a la futura representación nacional. Entre estos puntos se incluía también la participación que debían tener los americanos en las Cortes ${ }^{10}$. La comisión de que habla el decreto se formó con fecha de 8 de junio de 1809 y en la sesión de 19 de junio se planteó la cuestión de la convocatoria de las Cortes: si ésta debía ser por estamentos o sin distinción alguna de clases. Los tres votos de Jovellanos, el arzobispo de Laodicea y Francisco Castañedo inclinaron el dictamen a la reunión por estamentos, fundándose en las antiguas leyes y la tradición de la monarquía. Por su parte, Caro y Riquelme argumentaron que, puesto que las Cortes deberían ser una verdadera representación nacional y a ellas competían las reformas, éstas deberían reunirse según las costumbres más cercanas, es decir, que los representantes de las ciudades y villas tenían derecho a ser representadas. No fue suficiente para decantar la voluntad de la comisión, cuyo dictamen sobre convocatoria por estamentos fue aprobado en el seno de la Junta Central.

Pocos días después, la Junta Central decretaba la reunión de todos los consejos en uno solo. De este modo, los de Castilla, Indias, Órdenes y Hacienda quedaban refundidos en el Consejo de España e Indias ${ }^{11}$. Un nuevo golpe a los

FCE, 2007. Los poderes de México, Nueva Granada, Perú y Puerto Rico fueron publicados en el apéndice documental del trabajo de CASTEL, Jorge La Junta Central Suprema y Gubernativa de España e Indias. Su creación, organización y funcionamiento, Madrid, Marto, 1950.

${ }^{9}$ La comisión estuvo compuesta por el arzobispo de Laodicea, Gaspar Melchor de Jovellanos, Rodrigo Riquelme, Francisco Javier Caro y Francisco de Castanedo. Como secretarios de esta comisión se eligió a Manuel de Abella -oficial de la secretaría del despacho universal de Estado-y a Pedro Polo de Alcocer -oficial de la de Guerra.

${ }^{10}$ Archivo del Congreso de los Diputados de Madrid, Serie General, exp. 1, leg. 1.

${ }^{11}$ El estudio más reciente del Consejo en profundidad se debe a PUYOL MONTERO, José María "La creación del Consejo y Tribunal Supremo de España e Indias (Consejo reunido), por la Junta Central en 1809", Cuadernos de Historia del Derecho, n 12, 1995, pp. 189-236. También existe un trabajo anterior de SÁNCHEZ-ARCILLA BERNAL, José "El Consejo y Tribunal Supremo de España e Indias (1809-1810). (Notas para su estudio), en La España medieval, tomo V, Madri: Editorial de la Universidad Complutense, 1986, p. 1033-1050. 
consejeros que ya habían visto reducido su poder con el nombramiento de la Junta de Gobierno por parte de Fernando VII y después con la reunión de la Central. Pero además, lo que verdaderamente importunaba al Consejo era la "apropiación" que la Junta Central había hecho de la soberanía. Sus palabras desvelan que la voluntad del Consejo había sido que las provincias enviaran sus vocales para votar la erección de un gobierno interino, léase Regencia, que asumiese el poder. Para ello, condescendió con la reunión de las juntas provinciales y de sus diputados. Éstas eran sus palabras:

[el consejo] expuso a todas las provincias el género legal de gobierno que convenía [...] e invitó a las juntas superiores a que sus mismos diputados eligiesen un gobierno legal interino en nombre de la nación, [...] les concedió por entonces el concepto que verdaderamente no tenían, pero fue indispensable esta política de condescendencia. [...]

Tuvo efecto la congregación de los comisionados provinciales en Aranjuez. El consejo ignora los términos de sus respectivos poderes, sin embargo de pertenecer según ley a la Real cámara su reconocimiento; y el resultado fue que sin preceder informe ni dictamen suyo se formó la actual suprema junta central de España e Indias, con el ejercicio interino de la soberanía ${ }^{12}$.

El problema, por lo tanto, residía en la soberanía. Y eso evidencia la magnitud de la crisis política, pues no se trata tan sólo de quién era el titular de esta soberanía, sino de, en nombre de quién y cómo se ejercía la misma. Porque, ¿acaso era lo mismo que fuera el Consejo Real -una institución del Estado absoluto-, quien ejerciera la soberanía en nombre del rey, que lo hiciera una junta elegida "popularmente" desde las provincias y de forma proporcional? Es evidente que no.

Pero además en la consulta, el Consejo exigía el nombramiento de un gobierno provisional, a la cabeza del cual debería colocarse un Borbón, y para ello sugería la persona del arzobispo de Toledo y Sevilla, Luis de Borbón, el único miembro varón de la familia real que se encontraba en la península ${ }^{13}$. La

\footnotetext{
${ }^{12}$ FERNÁNDEZ MARTÍN, Manuel. Derecho parlamentario español. Madri: Publicaciones del Congreso de los diputados, tomo 1, 1992, p. 500.

${ }^{13}$ Luis de Borbón era primo de Carlos IV y cuñado de Godoy y ya había sido propuesto por Jovellanos, en su exposición de 7 de octubre de 1808, para ocupar la presidencia de una futura Regencia. También, sonó su nombre para presidir la Junta de Gobierno que dejara Fernando VII, pero éste
} 
Junta, debería nombrar a cuatro consejeros para que conformasen este gobierno y depositar en ellos el ejercicio de la soberanía. En eso era tajante el Consejo. Y planeando ya los antecedentes de la futura Regencia, insistía también en la inclusión de algún miembro americano en el gobierno.

Parece ser que esta consulta del Consejo provocó una gran discusión en el seno de la Junta Central. De estas discusiones ha trascendido el voto particular de Lorenzo Calvo de Rozas, vocal por Aragón, emitido el 7 de septiembre de 1809, quien insistió en la soberanía legítima de la Central, concedida por el pueblo y que ésta regresaría al mismo a través de su representación en Cortes. El vocal, además, reconocía que la histórica Constitución española, si bien era "un monumento precioso de la historia nacional", estaba muy lejos de acercarse a las nuevas teorías filosóficas y políticas. E insistía en que, a pesar de la proclamación de Fernando VII, lo cierto era que ésta fue "una nueva elección" de un rey desde el cuerpo político que lo había reconstituido cuando los lazos de unión se habían roto. Es decir, Calvo de Rozas, en un discurso profundamente liberal, asumía la proclamación de Fernando VII como un acto de elección del cuerpo político, que en ausencia del monarca y por la vía revolucionaria, había asumido la soberanía popular. Exactamente igual a lo que harían las Cortes de Cádiz en la noche del 24 de septiembre de 1810 como primer acto de su constitución. Y añadía, que la Junta Central tenía la capacidad legislativa de abrogar o modificar las leyes, incluidas las Partidas, defendiéndola al mismo tiempo de la acusación de ser "adicta al poder". Junto a esto, rechazaba la propuesta de que el cardenal Luis de Borbón fuera el presidente de la futura Regencia. Al ser el único miembro varón de la familia real que estaba en la península, Calvo sugería que podría reclamar su derecho al trono, y eso, había que evitarlo a toda costa. El vocal concluía solicitando la reunión de las Cortes para el 1 de noviembre inmediato y que se reprobara al Consejo por sus expresiones. Pero también que se castigase a toda autoridad militar o civil y que se extinguiese toda junta o cuerpo que directa o indirectamente eludiera los mandatos de la Central. Esto último era consecuencia de las primeras críticas que recibió la Junta Central de las provincias hacia agosto de 1809, fundamentalmente de Valencia,

prefirió al infante Don Antonio. Cuando sí presidirá una junta de gobierno será en 1820, con la formación de la Junta Provisional Consultiva que gobernó de marzo a julio de ese año. Sobre la figura de Luis María de Borbón, véase LÓPEZ-BREA, Carlos M. Rodríguez. Don Luis de Borbón. El cardenal de los liberales (1777-1823). Toledo: Junta de Castilla La Mancha, 2002. 
Aragón y Sevilla ${ }^{14}$. Esto se debía en parte a las medidas liberales que aplicaba la Central y, por otro lado, a las campañas orientales del ejército francés en esa zona desde finales de 1808 .

Tanto la consulta del Consejo como el voto de Calvo de Rozas provocaron los debates en torno al tema de la Regencia en el seno de la Junta Central. Sin embargo, apenas una semana después, el 14 de septiembre, volvía el vocal aragonés a insistir en la inmediata reunión de las Cortes para principios de noviembre. Y es que desde el decreto de 22 de mayo habían pasado casi cuatro meses en los que no se había avanzado nada en el tema de la convocatoria. El asunto se perfilaba urgente. Pero además, en su exposición, Calvo pedía que se determinara cuál era el principio que había de servir de base a la representación nacional, para que se avisara al público y la maquinaria electoral se pusiera en marcha de forma inmediata. Pero, ¿qué significaba esto? ¿No había determinado -en 22 de junio- la comisión emanada de ese decreto que la convocatoria se realizara por estamentos? ¿A qué venía ahora inquirir de nuevo sobre la misma cuestión?

Fruto de estas discusiones, la Central dio un manifiesto fechado el 28 de octubre de 1809 donde se fijaba una convocatoria para el 1 de enero del siguiente año y la reunión de las Cortes a partir de marzo. En él, también trataba los temas que habían suscitado mayor debate dentro y fuera de la Junta, sobre todo, la posible reunión de una Regencia. El manifiesto indicaba que la situación creada a partir de mayo de 1808 no podía compararse a ninguno de los casos en los que las antiguas leyes explicitaban la necesidad de reunir un gobierno regente. Y puntualizaba: "Una posición política, nueva enteramente, inspiró formas y principios políticos absolutamente nuevos”. Esto es, la Junta se sintió siempre como un poder distinto, cualitativamente distinto, y por ello revolucionario, al que representaban otras instituciones del Antiguo Régimen. Por eso, además, utilizaba el nombre de "Asamblea" para autodenominarse a lo largo de todo el manifiesto, queriendo presentar cierto paralelismo con el poder revolucionario francés ${ }^{15}$. Es decir, reunión de hombres libres e iguales, como rezaba la literatura de la época.

\footnotetext{
${ }^{14}$ HERNANDO SERRA, María Pilar. El ayuntamiento de Valencia y la invasión napoleónica. Valencia: Publicacions de la Universitat, 2004. Un estudio ya clásico es GENOVÉS AMORÓS, Vicent. València contra Napoleó. Valencia: L'Estel, 1967.

${ }^{15}$ También para Miguel Artola el poder de la Junta Central fue revolucionario y rupturista con las anteriores formas de gobierno. ARTOLA, Miguel La España de Fernando VII, Historia de España de Ramón Menéndez Pidal. Madri: Espasa Calpe, XXXII, 1976.
} 
Junto a esto, aludía al modo de convocar las Cortes, insinuando que no debía hacerse por estamentos: [...] "es bien superfluo, por no decir malicioso, recelar que las Cortes venideras hayan de estar reducidas a las formas estrechas y exclusivas de nuestras Cortes antiguas. Sí españoles, vais a tener vuestras Cortes, y la representación nacional en ellas será tan completa y suficiente cual deba y pueda ser en una Asamblea de tan alta importancia y tan eminente dignidad"16.

Y para acallar los rumores de los que acusaban a la Central de querer mantener el poder, propuso el nombramiento de un poder ejecutivo dentro de la Junta. La sección ejecutiva se formó el 1 de noviembre inmediato con el marqués de la Romana, Rodrigo Riquelme, Francisco Caro, Sebastián Jocano, José García de la Torre y el marqués de Villel ${ }^{17}$. Las necesidades acuciantes de una dirección ejecutiva para los asuntos de la guerra -las últimas jornadas de Ciudad-Real y Medellín habían sido desastrosas para las armas españolas y aún quedaba por venir la derrota de las fuerzas españolas en Ocaña, (Guadalajara)- auspiciaron la creación de esta sección ejecutiva que se renovó a los dos meses.

En aquellas fechas se nombraba también la junta para el ceremonial de las Cortes cuyos miembros discutieron entre noviembre y diciembre sobre el asunto de la existencia de una o dos cámaras ${ }^{18}$. El 5 de diciembre emitían su dictamen enviado a la comisión de Cortes en el que se acordaba que la reunión fuera en una sola cámara y que para mantener la distinción de estamentos se asignaran asientos diferenciados al clero (a la derecha del presidente) y a la nobleza (a la izquierda del mismo). Como vemos, el razonamiento de la reunión mantenía la idea original de la convocatoria por brazos, sin embargo, la comisión establecía que el clero sólo podía estar representado por sus arzobispos y obispos, y la alta nobleza por medio de los Grandes de España, dejando que el tercer estado se compusiera del resto de títulos y nobles y los que fueran elegidos libremente

\footnotetext{
${ }^{16}$ Manifiesto fijando los dias en que se han de convocar y celebrar las Cortes generales de la monarquía española, fecha 28 de octubre de 1809.

${ }^{17} \mathrm{Al}$ formar parte de la sección ejecutiva, Riquelme y Caro fueron relevados de sus cargos en la comisión de Cortes y sustituidos en ella por Martín de Garay y el conde de Ayamans. Tal vez fuera casualidad o no, pero justamente Riquelme y Caro habían sido los dos que no habían aceptado la convocatoria por estamentos en las discusiones del mayo anterior. Los nombres de los vocales en CASTEL, Jorge La Junta Central Suprema y Gubernativa de España e Indias. Madri: 1950, p. 83.

${ }^{18}$ De ella formaron parte el conde de Ayamans, Sebastián de Torres, Manuel Abella, Pedro Polo de Alcocer, Antonio Capmany, Vicente Eulat, Alejandro Dolarea y José Ramírez de Cotes como secretario. Esta junta quedó constituida el 21 de noviembre de 1809. Véase el estudio de SUÁREZ, Federico. El proceso de la convocatoria a Cortes (1808-1810). Pamplona: Eunsa, 1982.
} 
para el cargo. Pero además, impedía que el clero regular y secular pudiera concurrir a la representación del tercer brazo. Y para equilibrar las fuerzas entre los brazos, añadía que los votos de los eclesiásticos y nobles no podían exceder de la tercera parte del total. Sin embargo, este informe no convenció a la comisión de Cortes, que en 18 de diciembre, envió a la Central una exposición insistiendo en la necesidad de reunir las dos cámaras ${ }^{19}$.

\section{Una convocatoria exclusiva para los americanos}

Por su parte, la elección de suplentes para los americanos fue tratada también en la comisión de Cortes. Para dilucidar este asunto, se había encargado a algunos consejeros que emitieran sus opiniones por escrito al respecto. Los votos particulares de los consejeros llegaron con fecha de 7 de diciembre de 1809 y fueron los de Joaquín Mosquera, Miguel de Lardizábal, Esteban Fernández de León, Silvestre Collar, Francisco Requena y José Pablo Valiente ${ }^{20}$.

Joaquín Mosquera optó por una designación de personas que defendieran los derechos de los americanos, arguyendo el escaso número de éstos que existía en la península. En su voto, recordaba las relaciones de vasallaje que unían a estos territorios con el Rey, y por lo tanto, como la Junta era la depositaria de la soberanía real, correspondía a ella realizar el nombramiento. E indicaba: "que lo que así se hiciera surtiría los mismos efectos que si los diputados nombrados por las Provincias asistiesen a las Cortes, pues se procedía de un modo legal y muy conocido en el derecho". Es decir, Mosquera se manifestaba abiertamente contrario a considerar a los americanos en calidad de igualdad de derechos respecto de los peninsulares. En cuanto al número admitía que lo correcto sería que se fijase la representación americana en un tercio de la peninsular, y para ello, había que esperar a saber cuántos diputados debían concurrir a las Cortes por la península.

Por su parte, Miguel de Lardizábal, aunque novohispano de nacimiento, no se aventuraba a establecer un sistema electoral para el caso, opinando que, de momento, fueran los diez vocales nombrados para la Central los diputados

\footnotetext{
${ }^{19}$ Este informe estaba firmado por JOVELLANOS, Castañedo. Martín de Garay y el conde de Ayamans.

${ }^{20}$ Fernández Martín los transcribe en su obra, a excepción de uno que queda resumido. También Federico Suárez indica el contenido de estos votos, aunque se limita a resumirlos sin ir más allá en su interpretación. SUÁREZ, F. El proceso de la convocatoria a Cortes, p. 410-417.
} 
interinos en las Cortes. Pero el factor tiempo era crucial. La reunión del Congreso estaba prevista para el 1 de marzo, y no parecía que para aquella fecha fueran a llegar si quiera los vocales nombrados para la Junta. De este modo, Lardizábal exponía que la Junta debía elegir suplentes de entre los que residían en la península, exigiéndoles el requisito de la naturaleza americana. Concluía el consejero indicando que el número de diez diputados le parecía bastante escaso, añadiendo a éste otros siete: uno al virreinato de Santa Fe, otro al del Río de la Plata, dos al Perú y tres a Nueva España.

Esteban Fernández de León propuso que las juntas provinciales recabaran información acerca de los naturales de América que existieran en sus provincias. De este modo, se podían establecer unas listas en las que se consignara el nombre, edad, calidad, estado, vecindad, bienes, oficio, instrucción y demás conocimiento necesario para proceder a la elección. Este voto fue el que más influyó en la forma de llevar a cabo la elaboración de las listas y la elección, como veremos.

Fernández de León opinaba que era mejor que la elección la realizaran los propios americanos entre ellos, convocándoseles por medio de la Gaceta del Gobierno para que todos concurrieran en Sevilla el día prefijado para la elección. En caso de no poder acudir a la ciudad, se podían remitir los votos por correo dirigiéndolos al secretario de la comisión de Cortes. Respecto al número de diputados, lo elevaba hasta 26, repartidos de la siguiente forma: seis para el virreinato de Nueva España incluyendo las provincias internas, Yucatán y Campeche, cuatro para el Perú (incluyendo Chile), tres para Santa Fe, tres para el Río de la Plata, dos para Guatemala, dos para la provincia de Caracas, dos para Cuba y las Floridas, uno para Puerto Rico, otro para Santo Domingo y dos para Filipinas. También era de la opinión de que se prefiriera a los que llegaran elegidos para la Junta Central hasta que asistieran los titulares de las Cortes. Pero el número nunca debía superar los veintiséis, saliendo por sorteo aquellos suplentes que estuviesen ejerciendo el cargo a la llegada de los propietarios.

Por su parte, Silvestre Collar opinaba que el método para realizar las elecciones en América debía ser el mismo que el que se utilizara en la península, pero mientras esto se producía, no dudaba en que la elección de suplentes de entre los americanos residentes era la mejor opción.

El 11 de diciembre expuso José Pablo Valiente su voto. Lo primero que expresó fue su júbilo al ver que la comisión preveía la representación americana, para así 'evitar el disgusto que los naturales de dichos dominios habían de tener 
necesariamente, al ver que de modo alguno se contaba con ellos" [...]. Valiente explicaba que muchos americanos que él conocía habían leído con disgusto el decreto de 22 de mayo en el que se dejaba a las futuras Cortes la decisión de la elección de representantes americanos, lo cual significaba que para esta primera convocatoria no serían tenidos en cuenta. Por su parte, consideraba que la participación de "los principales de allá" era indispensable para que conocieran el buen funcionamiento del gobierno, se instruyeran de las costumbres, hicieran amigos, se casaran, etc., todo para fomentar un sentimiento mutuo de confianza y pertenencia a una misma realidad. Valiente hizo gala de sus conocimientos de la realidad americana por haber vivido varios años en Guatemala, Nueva España y Cuba y concluyó que se debía conceder igual representación a la América septentrional que a la meridional, a pesar de las diferencias entre ambas. Respecto al número de representantes, Valiente consideraba que 28 era justo, distribuyéndolos de la siguiente forma: siete por Nueva España, dos Guatemala, dos Cuba, uno Puerto Rico, dos Filipinas, cuatro Perú, dos Chile, tres Río de la Plata, tres Santa Fe, y dos por Caracas. Para finalizar, insistía, como los otros, en que los elegidos debían ser naturales de los dominios americanos y a ser posible, del territorio que iban a representar.

El último voto que se envió a la comisión fue el de Francisco Requena, emitido el 12 de diciembre. Al igual que Fernández de León, Requena proponía que los americanos residentes en la península enviaran una relación a la Junta Central presentándose e informando de su lugar de nacimiento, edad, educación, estudios, empleos y demás datos necesarios para formarse una idea de cada uno de ellos. De este modo, pensaba el consejero, que se probaría la imparcialidad en la elección de aquellos que presentaran mayores talentos para ejercer el cargo, sin detenerse en que fueran de una u otra clase. Para la forma de elección, Requena pensaba que no debía ser igual a la de la península, es decir, basada en la población, sino que se debía atender a cuestiones de tipo geográfico. Pero la aportación más interesante la hizo Requena respecto a la participación de la población americana en la representación. En su argumentación hacía patente la diversidad racial americana:

[...] Se regulan en la América e islas Filipinas catorce millones de almas bajo la dominación de S.M.: entre estas están los blancos en razón de dos a nueve con los indios negros, y demás castas de colores intermedias; por consiguiente ascienden los primeros a tres millones y un noveno entre españoles, europeos y americanos y los diez millones ocho novenos 
restantes son de indios negros y gentes de las otras diferentes mezclas. De este último número de personas, puede desde luego computarse como siete millones de ellas, imbéciles por recién convertidos, miserables y esclavos, pues los de esta sola última clase componen la vigésima parte de la población de aquellos dominios, de lo que se deduce que de los otros siete millones se han de extraer las cabezas de familia y hombres de mas de 25 años, representables para la elección de sus diputados ${ }^{21}$. [...]

Esto es, según los cálculos de Requena, en la elección de diputados americanos podían participar no sólo los españoles y criollos sino también los indios, cabezas de familia varones y mayores de 25 años. Adelantaba así, el debate posterior en las Cortes de Cádiz acerca de la participación o no de los indios y castas en la representación nacional. Sin embargo, y a pesar de que la población americana superaba a la peninsular, Requena también reducía el número de diputados americanos a veintiséis. En su división, concedía dos diputados de forma proporcional a cada uno de los territorios -Santa Fe, Reino de Quito, Lima, Buenos Aires, Chile, Caracas, Guatemala, Puerto Rico, Cuba y las Floridas y Filipinas-, a excepción del virreinato de Nueva España, al que asignaba seis porque su población correspondía a la tercera parte del total y porque su territorio, englobando las provincias internas, era mayor.

Al igual que el resto de los votos expresados, Requena priorizaba a los vocales elegidos para la Central para ser diputados por América y para la elección del resto señalaba que se debía atender el requisito expreso de naturaleza. Cuando no existieran suficientes naturales de algún territorio podían suplirse con diputados nacidos en otras partes de América cercanas a la jurisdicción que debían representar. Pero si ocurriera el caso de que tampoco así fuera suficiente, se podrían elegir diputados naturales de la península que hubieran adquirido conocimiento y experiencia de su estancia en América. El consejero añadía, además, que se incitara a todos los americanos que, aunque no fueran elegidos diputados, contribuyeran con sus memorias y escritos a instruir al gobierno con noticias de aquellos territorios.

Dos días después de que llegara el último de los votos consultados a la comisión de Cortes, su secretario, Manuel Abella, pasaba oficio al gobernador y consulado de Cádiz, a las juntas de Sevilla, Valencia, Granada, Córdoba, Jaén

${ }^{21}$ MARTÍNEZ, Fernández. Derecho parlamentario, tomo 1, p. 580. 
y al ministro del Consejo Antonio Ignacio de Cortabarría -que se hallaba en Málaga-para que remitieran a la mayor brevedad las listas de los naturales de América que se encontraran en sus provincias.

Mientras tanto, el 19 de noviembre de 1809 se había producido la importante derrota de Ocaña para las tropas aliadas anglo-españolas, como hemos mencionado anteriormente. El ejército francés reordenó sus posiciones, inició la ofensiva oriental en Aragón y Cataluña y se preparó para entrar en Andalucía a principios del año 1810. El tiempo apremiaba y la Junta Central debía despachar de forma urgente el asunto relativo a la convocatoria, puesto que la fecha para reunirse las Cortes se había fijado en el 1 de marzo. A tales efectos, el 1 de enero de 1810 se publicaron tres decretos de convocatoria y la instrucción detallada para la elección de diputados. Un decreto dirigido a las Juntas provinciales para que eligieran un diputado según las reglas establecidas en el capítulo quinto de la instrucción. Otro, dirigido a las ciudades de voto en Cortes para que procedieran de igual forma a la elección de un diputado con arreglo al capítulo sexto de la instrucción. Y el tercero suponía la convocatoria general para los diputados provinciales, es decir, para el estamento general ${ }^{22}$. Respecto a los americanos, el 2 de enero se publicó en la Gaceta del gobierno el aviso para que remitieran sus informes al secretario Manuel Abella para postularse como candidatos a la representación.

Entretanto, los acontecimientos bélicos obligaron a la Junta a salir de la ciudad de Sevilla y trasladarse a Cádiz y la Real isla de León para garantizar la seguridad de sus miembros. A partir de aquí, la presión de quienes habían insistido en la reunión de un cuerpo ejecutivo consiguió que la Junta Central nombrara una Regencia de cinco miembros y procediera a autodisolverse. Ante de eso, el 29 de enero de 1810, expedía un decreto en el que se explicaba la forma de convocar las Cortes y de realizar las elecciones de los suplentes. En este importante decreto, la Junta detallaba la forma de elección de los suplentes americanos:

[...] la regencia formará una junta electoral, compuesta de seis sujetos de carácter, naturales de aquellos dominios; los cuales poniendo en cántaro

\footnotetext{
${ }^{22}$ La Instrucción del estamento popular detallaba el sistema electoral en tres niveles y establecía los cupos de población por provincias. El documento íntegro puede consultarse en FERNÁNDEZ MARTÍN, Manuel. Derecho parlamentario, tomo 2, p. 574-590.
} 
los nombres de los demás naturales que se hallan residentes en España, y constan de las listas formadas por la comisión de córtes, sacarán a la suerte el número de cuarenta, y volviendo a sortear estos cuarenta solos, sacarán en segunda suerte veinte y seis, y estos asistirán como diputados de córtes en representación de aquellos vastos paises ${ }^{23}$.

Como vemos, en el decreto se reducía el número de americanos a veintiséis en lugar de veintiocho como había propuesto José Pablo Valiente. Pero además, se determinaba la reunión en dos estamentos, uno popular y otro de dignidades y el derecho de veto para la Regencia. La Junta disponía, también, la reunión de una diputación de Cortes compuesta por seis peninsulares y dos americanos, que se encargara de realizar todos los preparativos para la reunión. La polémica suscitada por este decreto se debe más a su posterior "desaparición" que al contenido del mismo. Posteriormente, el regente Miguel de Lardizábal acusó en su Manifiesto a Manuel Quintana, oficial de la Secretaría de la Junta Central, de haber ocultado el decreto de forma deliberada. Acusación que fue repetida también por José Joaquín Colón, decano del Consejo reunido en su exposición España vindicada ${ }^{24}$.

Es cierto que el decreto no se publicó en el momento en el que fue expedido y que una vez reunida la Regencia, correspondía a ésta agilizar los trámites de la convocatoria. Unos meses después, instada por la Junta de Cádiz y algunos diputados que ya se habían ido reuniendo en esa ciudad, la Regencia solicitó la información de todos los antecedentes respectivos a la convocatoria de las Cortes. Fue en ese momento, en junio de 1810, cuando se citó a Martín de Garay, quien había sido secretario de la Junta Central y Ministro de la Sección de Estado interino de la misma como hemos mencionado. Según el relato de Fernández Martín, Garay reconoció haber cometido "el error" de expedir separadamente la convocatoria para el Estado general y enviarla primero por parecerle que se necesitaba más tiempo para llevarla a cabo. Y, posteriormente, las circuns-

\footnotetext{
${ }^{23}$ Decreto de convocatoria de Cortes de 29 de enero de 1810, en FERNÁNDEZ MARTÍN, Manuel. Derecho parlamentario, t. 1, p. 614-620.

${ }^{24}$ LARDIZÁBAL, Miguel de. Manifiesto que presenta a la nación el consejero de Estado don Miguel de Lardizábal y Uribe, uno de los cinco que compusieron el Supremo Consejo de Regencia de España e Indias, sobre su conducta política en la noche del 24 de septiembre de 1810, Alicante, 1811. COLON, José Joaquín. España vindicada en sus clases y autoridades de las falsas opiniones que se le atribuyeron, Madrid, 1814. La polémica puede seguirse en SUÁREZ, F. El proceso de convocatoria, 1982, p. 427-438.
} 
tancias no le permitieron enviar las otras dos convocatorias a la nobleza y los prelados. Seguramente, las circunstancias a las que se refiere son su dimisión de los cargos que ejercía en la secretaría de la Junta y en la sección de Estado, admitida el 13 de octubre de 1809. Por lo tanto, enviada la forma de convocar al Estado general y no el resto, en todos los lugares se procedió a elegir a los diputados de esta manera, sin atender a la separación por estamentos decretada por la Junta. Y lo cierto es que fue así. Desde que el 1 de enero se expidieron los decretos para que las Juntas provinciales, las ciudades de voto en Cortes y las provincias eligieran sus diputados, ésos habían sido los únicos que se conocían oficialmente. De este modo, "la confusión" en la que había incurrido el público había sido la de conocer únicamente el decreto de convocatoria general y proceder a su cumplimiento.

La Regencia consultó además al Consejo de Estado sobre la forma de realizar la elección en las provincias ocupadas y el tema de los suplentes americanos. Al día siguiente, este Consejo opinaba que se dejara el tema a las Cortes para que éstas resolvieran sobre los suplentes. De este modo, a mediados de agosto, el problema más grave por resolver era el de los suplentes. Por un lado, el Consejo de Estado y la junta de Cádiz eran de la opinión de dejar el asunto en manos de las Cortes; por otro, el Consejo reunido y los diputados que ya habían llegado a Cádiz elegidos por sus provincias insistían en que se eligiera a los suplentes de entre los que estaban en las ciudades no ocupadas.

\section{Las listas de americanos}

Desde que la consulta de los consejeros para la formación de listas e informes sobre los americanos residentes en la península diera lugar a la noticia inserta en la Gaceta del día 2 de enero de 1810, Manuel Abella y el resto de autoridades de Cádiz, Málaga y demás zonas no ocupadas, no dejaron de recibir papeletas con la información solicitada. Inmediatamente, los americanos residentes en la península comenzaron a enviar sus informes, indicando su lugar de nacimiento, profesión, edad y demás cualidades para postularse como posibles diputados a las Cortes $^{25}$. La mayoría de los informes remitidos por los propios americanos

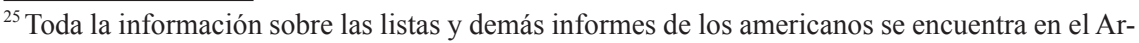
chivo del Congreso de los Diputados de Madrid, en el legajo 124, número 35 de los Expedientes generales. Esta información también ha sido analizada por RIEU MILLAN, Marie Laure. "La suppleance des deputes d'outre-mer aux Cortes de Cadix. Une laborieuse preparation", Melanges
} 
no son demasiado extensos e incluyen solamente la información fundamental, naturaleza, edad, empleo y residencia. Otros, sin embargo, describen detalladamente su formación, la familia a la que pertenecen, cuáles han sido los méritos obtenidos y sus condiciones para ser elegidos diputados. Entre las representaciones que le llegaron directamente a Manuel Abella, secretario de la comisión de Cortes, encontramos una diversidad bastante amplia del lugar de procedencia, edad y profesión. Por falta de espacio no podemos consignar aquí todos los nombres, pero analizando la documentación vemos que la mayoría de los que enviaron sus informes a Manuel Abella estaban por debajo de los cincuenta años, predominando las profesiones dedicadas a los empleos estatales y el ejército. Algunos ofrecían datos interesantes como Manuel del Sobrial y Bárcena, cuyo destino al momento de convocarse a los americanos era servir de intérprete a los prisioneros franceses que se encontraban curándose de sus heridas en el hospital provisional habilitado en la ciudad de San Carlos. Otros, como Pedro Vicente de Isasmendi, relataban su carrera militar en sus lugares de nacimiento, para pasar después a ejercer destinos en la península. Como indica Isasmendi, muchos de ellos debieron llegar de los territorios americanos reclutados para la guerra emprendida contra la Convención francesa en 1793.

De estos cincuenta americanos que presentaron sus cédulas a Manuel Abella, como veremos, tan sólo cuatro serán elegidos diputados suplentes en las Cortes: Andrés de Llano por Guatemala, Manuel Carrillo de Albornoz y Octaviano Obregón por México y el marqués de San Felipe y Santiago por Cuba. Otros, en cambio, que no serán elegidos en este momento, sí participarán en la segunda experiencia constitucional de los años veinte como Miguel Lastarria, José Domingo Benítez o Ignacio Pablo Sandino.

La información contenida en estas presentaciones resulta de especial interés para el caso de personajes que mantuvieron una actividad ferviente a lo largo de estos años y que serán protagonistas de la conformación política de sus Estados. Un caso paradigmático fue el del novohispano Servando de Mier y Noriega, quien formó parte activa del primer constituyente mexicano y cuya figura ha trascendido como uno de los republicanos federales más comprometidos en la historia de México. Servando de Mier refiere al secretario que nació en Monterrey, capital del Nuevo Reino de León y que su padre fue gobernador y comandante general. Seguidamente, explica su ascendencia por

de la Casa de Velázquez, t. XVII, 1987, p. 263-289. 
ambas líneas, reputándose como descendiente de los primeros conquistadores del reino y de la antigua nobleza indígena mexicana, y haciendo gala de sus antepasados españoles. ${ }^{26}$. Servando de Mier explica que llegó a la península en 1795 para resolver un pleito literario y destaca que en México había escrito en contra de las ideas de la Revolución francesa y del regicidio cometido con Luis XVI. Fue recomendado a Carlos IV por el papa Pío VII y sirvió diversos cargos en el consulado y embajada españoles en Lisboa. En septiembre de 1808 fue nombrado capellán del Batallón de voluntarios de Valencia, en compañía de quien se encontraba en la lucha contra los franceses, recibiendo varias recomendaciones de sus jefes militares por su valor en el campo de batalla. Pero además, Servando incidía en su idoneidad para ocupar el cargo de diputado. El ahora "fiel vasallo de su majestad" y deseoso de formar parte de las Cortes de la monarquía, mudaría su pensamiento en menos de quince años, declarándose ferviente republicano y criticando duramente la participación de los americanos en las Cortes de Cádiz y su Constitución. El ejemplo de Servando de Mier demuestra no sólo la complejidad del período que historiamos, sino que no podemos establecer compartimentos estancos para los personajes que participaron de los acontecimientos porque ellos y sus actuaciones, también están determinados históricamente.

También se formaron listas en Cádiz y Málaga, aunque la persona designada para elaborar el listado final de los americanos que debían concurrir a la elección era José Pablo Valiente, ministro del Consejo de Indias y ahora del Consejo reunido. El consejero informó en 14 de agosto de que convendría formar nuevas listas, pues sabía que después de las noticias que obtuvo la Junta Central, habían llegado más americanos. La Regencia, por su parte, instó a Valiente a que los padrones se formaran únicamente con los residentes en Cádiz y en la isla de León, lo que puede dar una idea de por qué en el listado del consejero se omiten muchos nombres que aparecen en las otras listas. Por esas fechas llegó la noticia de los sucesos de Caracas, conociéndose que se había erigido una junta y se llamaba a la rebelión abierta contra la Regencia por no considerar a ésta legítima en su formación ${ }^{27}$. Valiente tomó en cuenta esta información y consideró

\footnotetext{
${ }^{26}$ Su exposición era como sigue: "Que mi abuelo paterno era de Asturias de una casa magnaticia, casado en Monterrey con una nieta de los primeros conquistadores de aquel Reyno. Que mi abuelo materno era nieto de estos, y casado allí con una señora de la antigua nobleza magnaticia de México".

${ }^{27}$ Sobre esta cuestión véase el reciente estudio de QUINTERO, Inés. "Las juntas de Caracas"
} 
que el número de diputados suplentes por América debía elevarse a treinta, en lugar de los veintiocho que él había propuesto anteriormente. El aumento de estos dos diputados afectaba en uno al virreinato del Perú, que tendría cinco, y otro para la isla de Santo Domingo, contemplada ahora de forma exclusiva. Sus razones eran las siguientes:

[...] La ocurrencia de Caracas no embaraza ni debe embarazar para darle en este medio supletorio la representación posible en el modo que lo permite y exije el estado de las cosas: [...] Considerándosele dos diputados conforme a la consulta del consejo, dirán que ni son bastantes ni legales; pero mucho más dirían si se les excluyese del todo [...] seria con toda evidencia antipolítico y de unas funestas y duraderas resultas excluir a la provincia de Caracas de su representación en el medio supletorio: el es el unico que cabe en el estado presente: [...] Y en orden a la isla de santo Domingo, es justo y conveniente darle un diputado en el medio supletorio: serán 15 entonces por la América septentrional, pero ningún reparo podrá ofrecerse en dar cinco al territorio del virreinato de Lima por el mas extenso y el mas digno en razón de antigüedad y de quien por la mas facil administración y felicidad de aquella América, se desmembraron y erigieron los otros virreinatos y gobiernos separados ${ }^{28}$.

De este modo, al conceder un diputado más a la América septentrional, el de Santo Domingo, era necesario para respetar la igualdad, conceder también uno más a la América meridional, de ahí el aumento de uno para Perú, considerando su mayor extensión en el territorio. Los días 19 y 20 de agosto los dedicó la Regencia a tratar del asunto de la reunión de las Cortes decidiendo de forma definitiva que la convocatoria siguiera como estaba según el decreto de 1 de enero, es decir, que se reunieran en una sola cámara. En estos días también se aprobó que se admitiera a los diputados que llegaran de las provincias ocupadas y que entre los emigrados a Cádiz y la isla de León se eligieran los suplentes correspondientes a sus provincias. Respecto a los americanos, la Regencia establecía que los comprendidos en el padrón que vivieran en Cádiz y la isla

En: CHUST, Manuel (ed.). 1808. La eclosión juntera en el mundo hispano. México, FCE, 2007, pp. 334-355.

${ }^{28}$ El oficio de José Pablo Valiente en Fernández Martín, Derecho parlamentario, t. 1, pp.661-665. 
de León nombraran electores por cada virreinato y capitanía según se contenía en la instrucción de 1 de enero.

Con fecha 23 de agosto de 1810, el consejero elaboró y remitió el listado definitivo de los electores americanos a la Regencia. En ese listado aparecen consignados 165 nombres, a los que se suman doce nombres de la lista de la isla de León y de entre los cuales se realiza la elección definitiva de los 30 suplentes americanos para la primera legislatura de las Cortes de Cádiz. Los estudios dedicados a la participación de los americanos en las Cortes prácticamente no dan información respecto de esta elección ${ }^{29}$. La votación y elección de los suplentes americanos tuvieron lugar entre los días 20 y 22 de septiembre, como veremos más adelante.

Los nombres de los 165 americanos que merecieron la aprobación del consejero José Pablo Valiente para ser incluidos en la elección final fueron los siguientes:

\footnotetext{
${ }^{29}$ BERRUEZO LEÓN, María Teresa. La participación americana en las Cortes de Cádiz, (18101814), Madrid, Centro de Estudios Constitucionales, 1986, pp. 25-27. En realidad, la autora incurre en algunos errores de fechas y datos, pues primero indica las fechas de agosto para la elección y posteriormente afirma que fue en septiembre. Igualmente, considera en distintos momentos que el número de diputados fue de 28 , mientras en páginas siguientes afirma que fue de 30 . Por su parte Rieu-Millan ofrece el número de 177 electores americanos pero no da más información al respecto. RIEU-MILLAN, Marie Laure, Los diputados americanos en las Cortes de Cádiz, Madrid, CSIC, 1990, p. 5.
} 


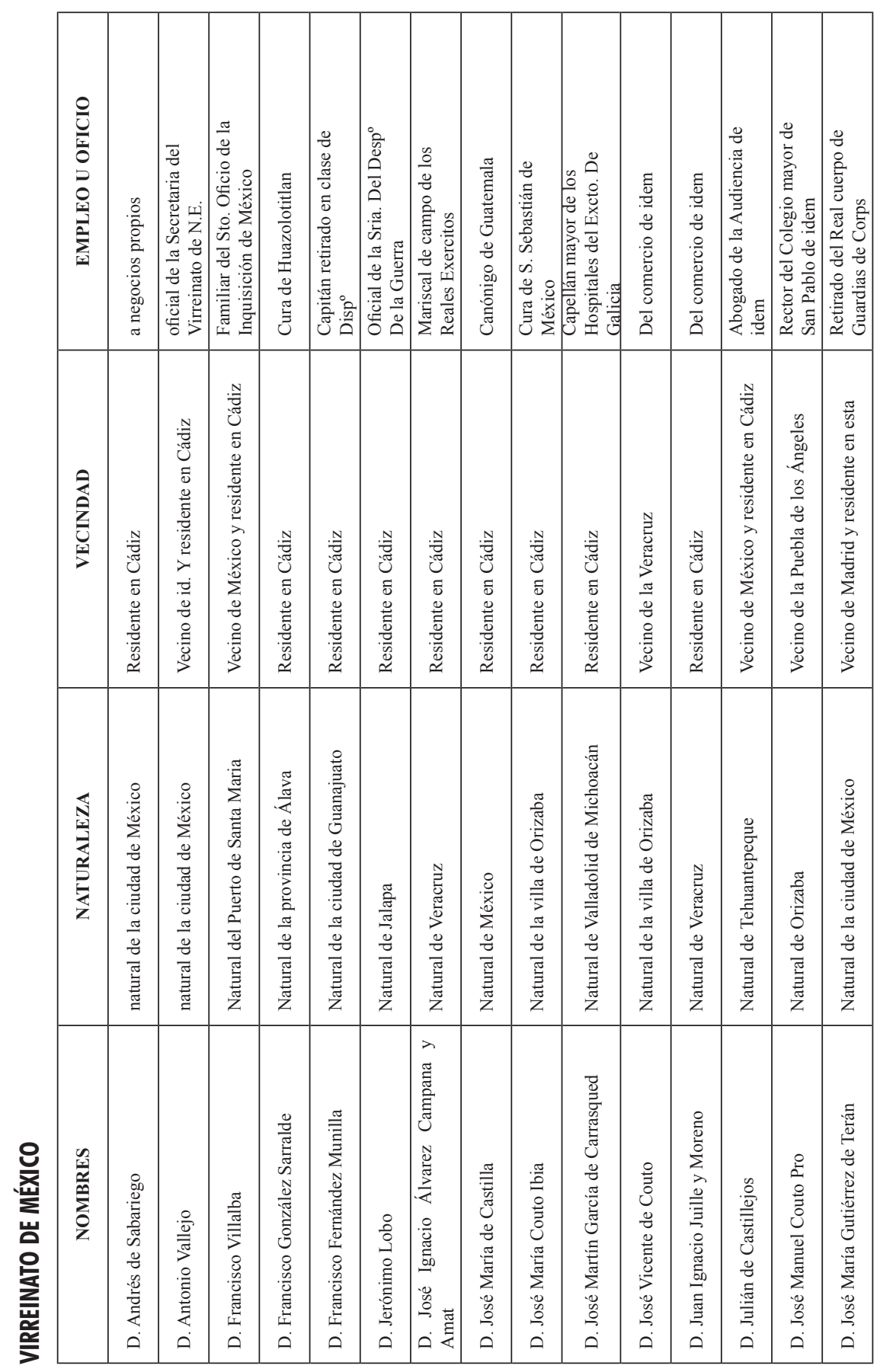




\begin{tabular}{|c|c|c|c|c|c|c|c|c|c|c|c|c|c|c|}
\hline 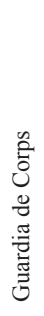 & 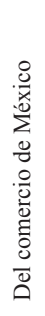 & 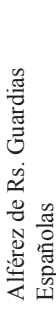 & 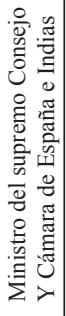 & 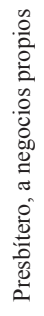 & 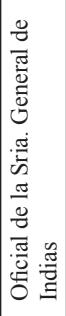 & 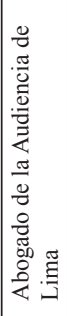 & 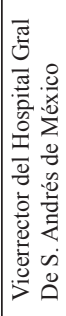 & 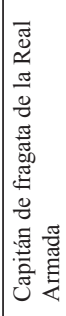 & 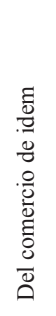 & 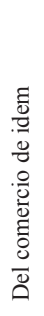 & 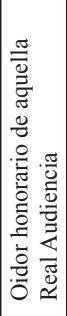 & 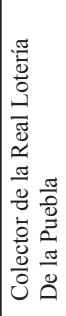 & 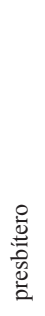 & 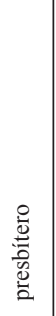 \\
\hline 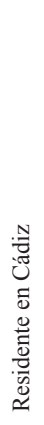 & 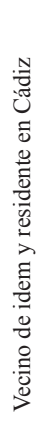 & 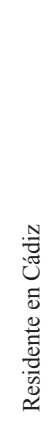 & 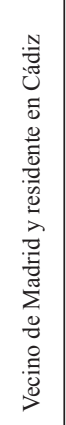 & 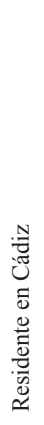 & 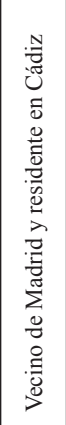 & 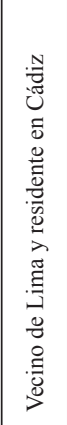 & 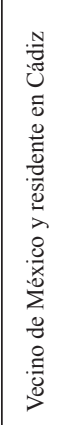 & 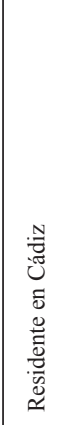 & $\begin{array}{l}: \text { N } \\
.00 \\
0 \\
0 \\
0 \\
.0 \\
0\end{array}$ & 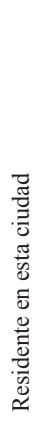 & 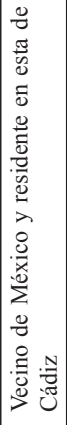 & 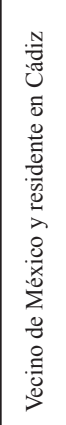 & 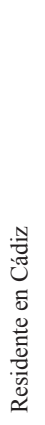 & 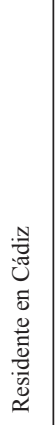 \\
\hline 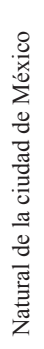 & 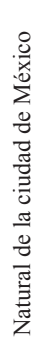 & 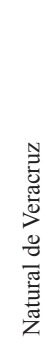 & 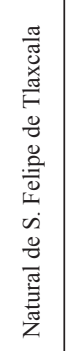 & 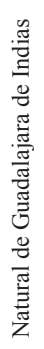 & 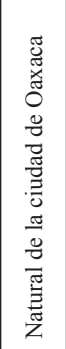 & 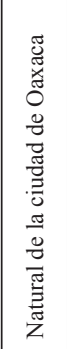 & 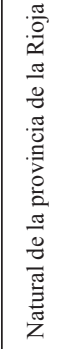 & 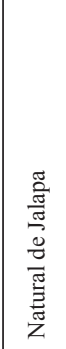 & 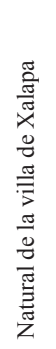 & 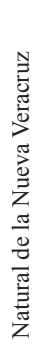 & 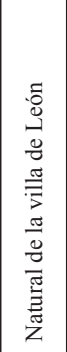 & 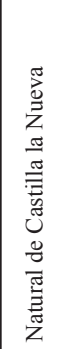 & 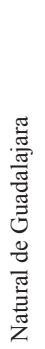 & 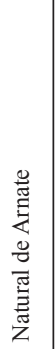 \\
\hline 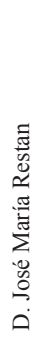 & 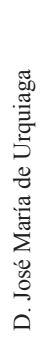 & 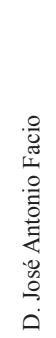 & 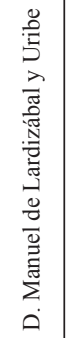 & 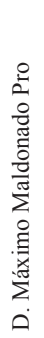 & 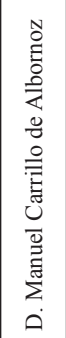 & 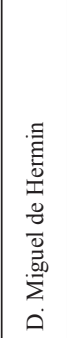 & 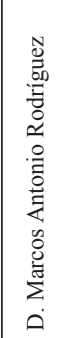 & 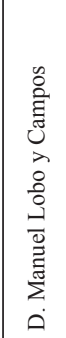 & 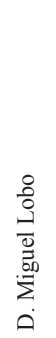 & 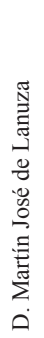 & 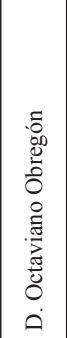 & 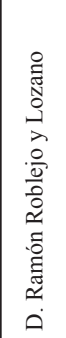 & 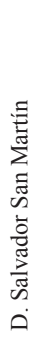 & 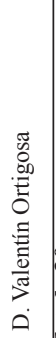 \\
\hline
\end{tabular}




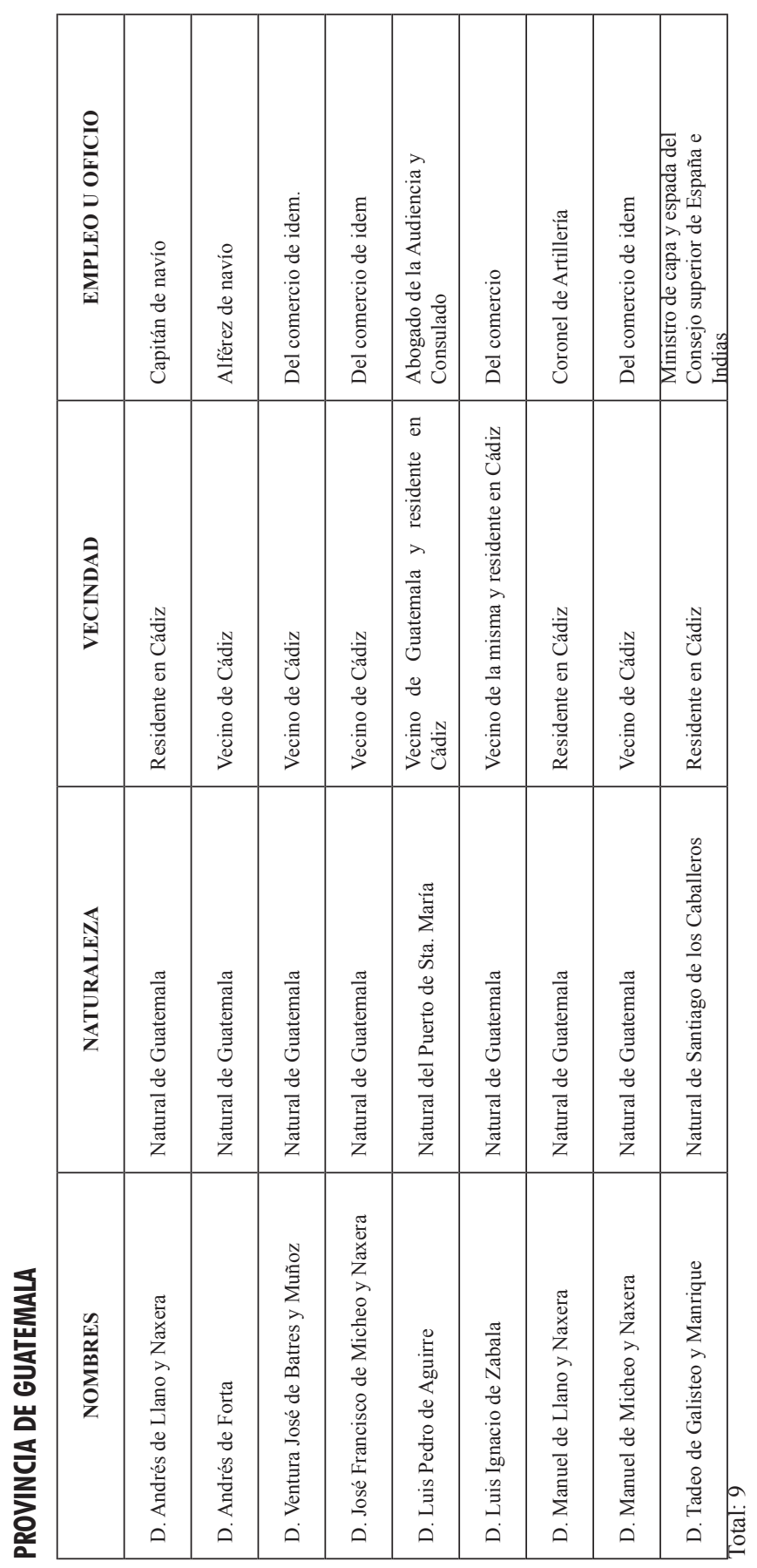



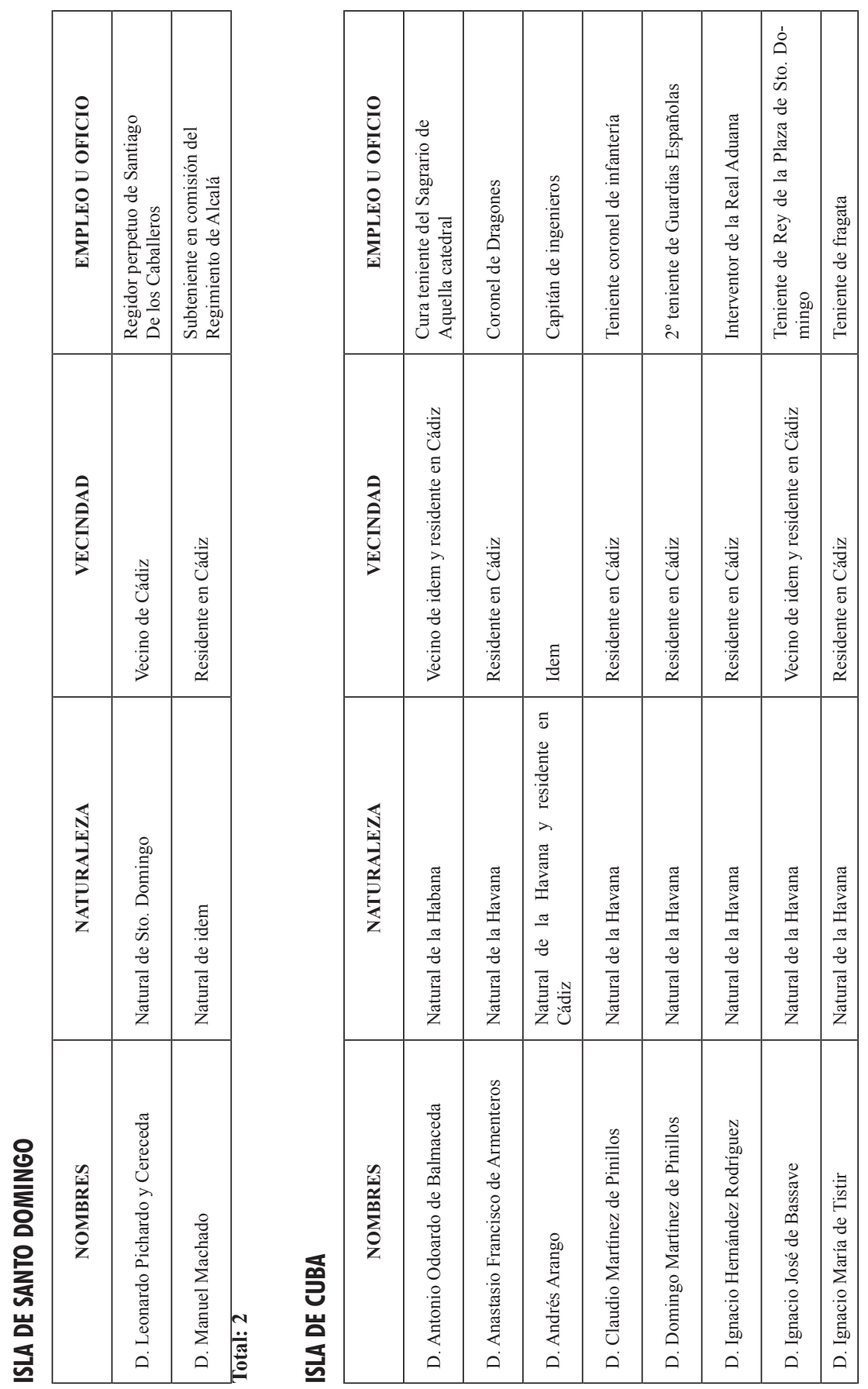


\begin{tabular}{|c|c|c|c|c|c|c|c|c|c|c|c|c|c|c|c|c|c|c|c|c|c|c|}
\hline 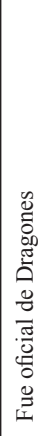 & 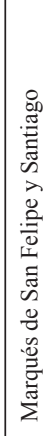 & 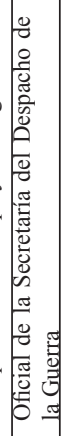 & 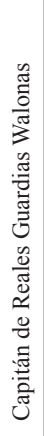 & 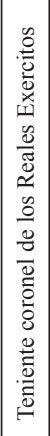 & 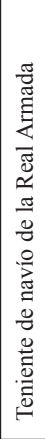 & & 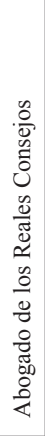 & 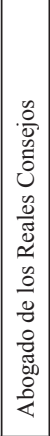 & 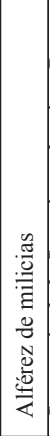 & 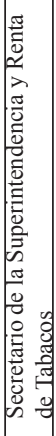 & 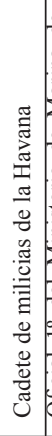 & 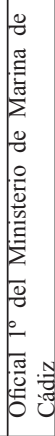 & 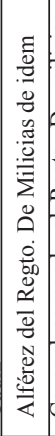 & 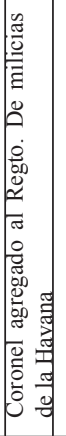 & & 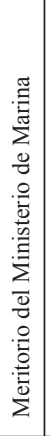 & 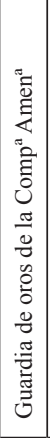 & 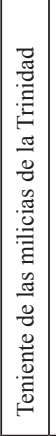 & 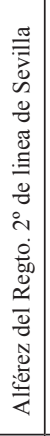 & 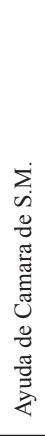 & & 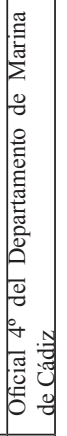 \\
\hline 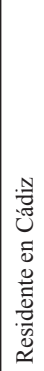 & 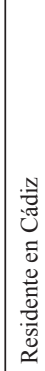 & 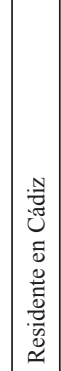 & 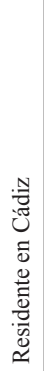 & 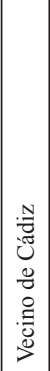 & 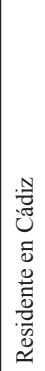 & 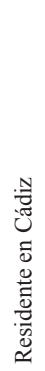 & 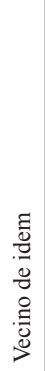 & 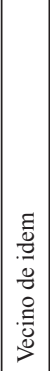 & 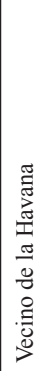 & 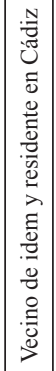 & 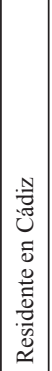 & 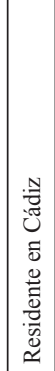 & 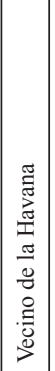 & 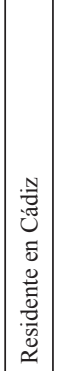 & 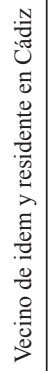 & 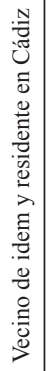 & 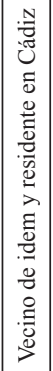 & 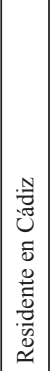 & 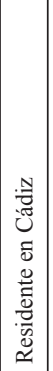 & 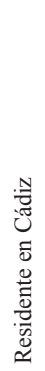 & $\stackrel{N}{z}$ & 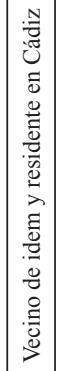 \\
\hline
\end{tabular}

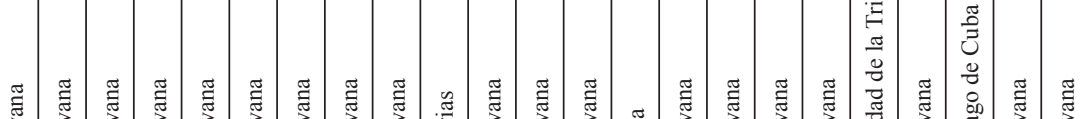
焉

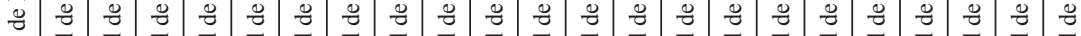

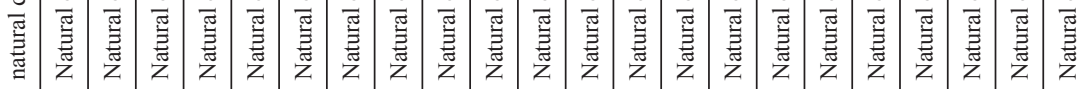

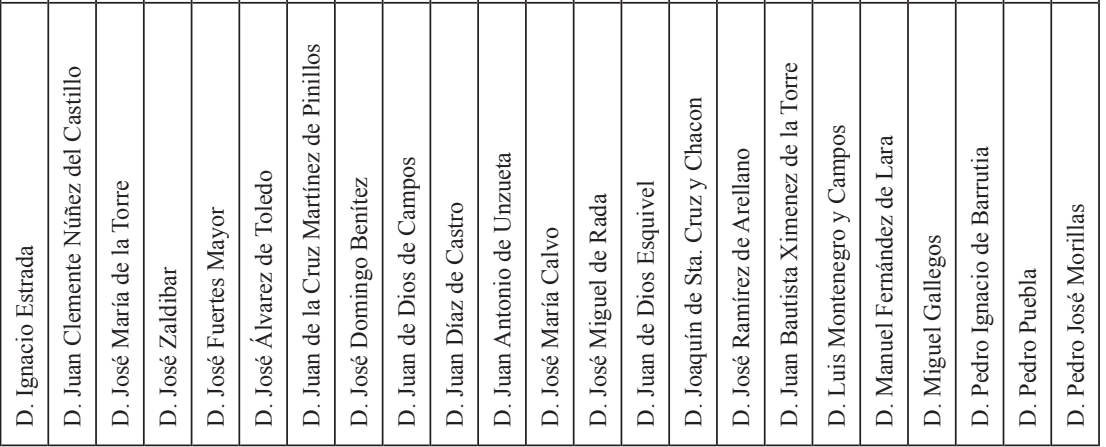



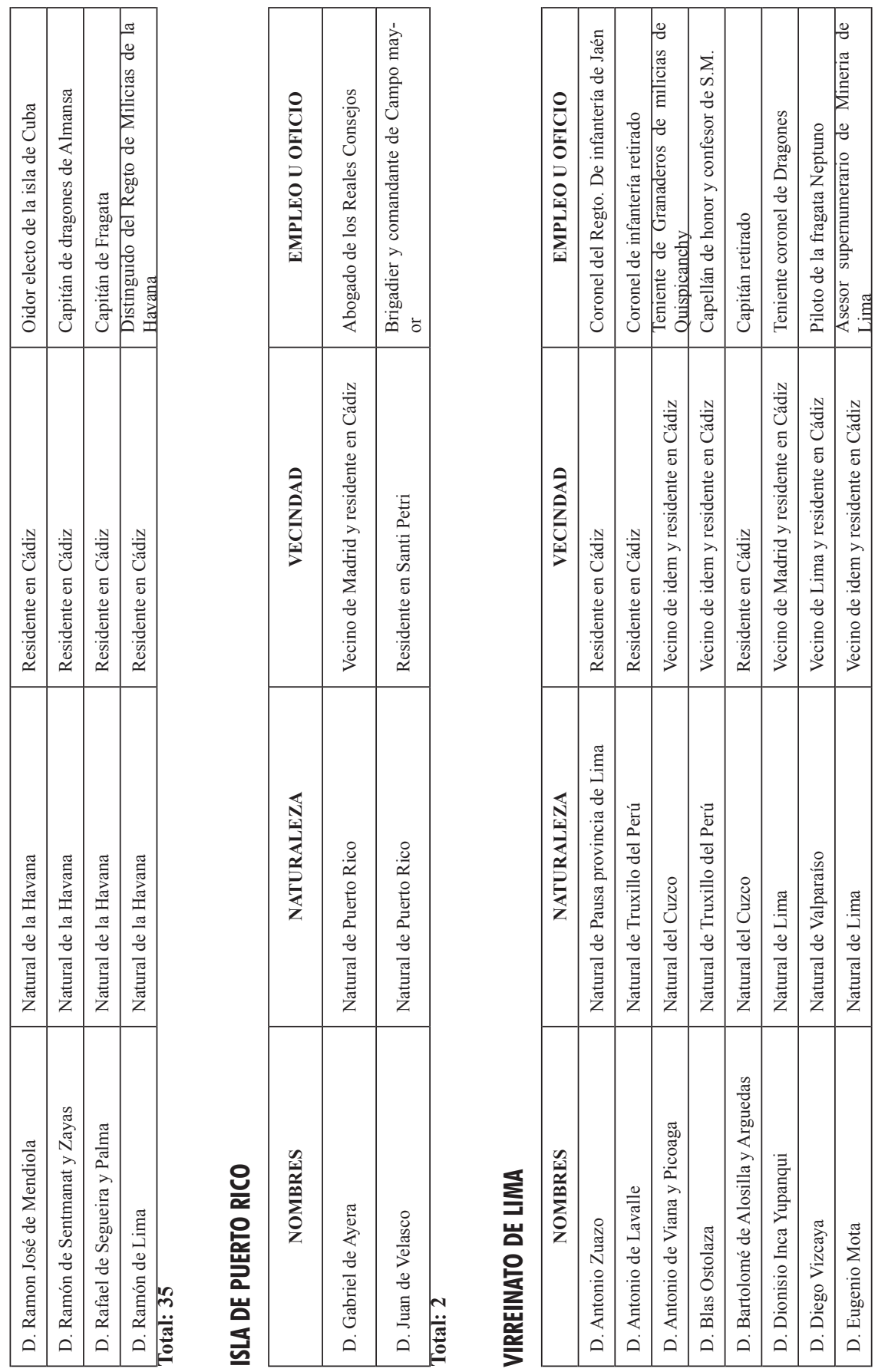


\begin{tabular}{|c|c|c|c|c|c|c|c|c|c|c|c|c|c|c|c|c|c|c|c|c|c|}
\hline 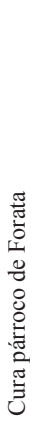 & 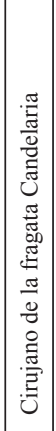 & 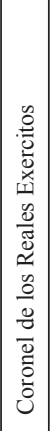 & 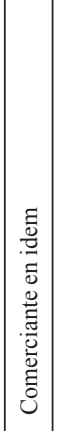 & 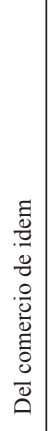 & 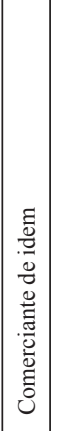 & & 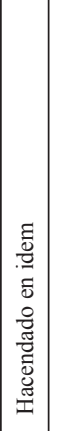 & 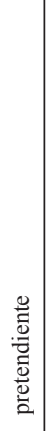 & 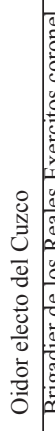 & 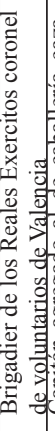 & 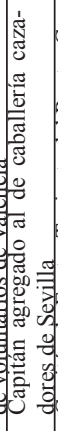 & 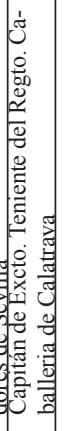 & 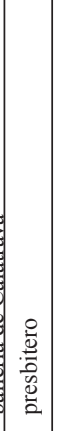 & 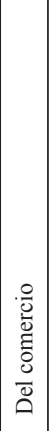 & 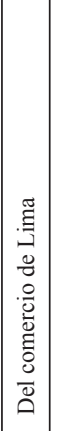 & 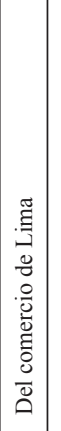 & 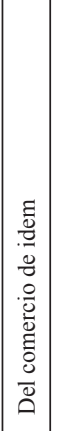 & . & 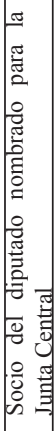 & 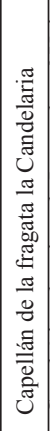 & 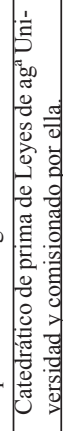 \\
\hline 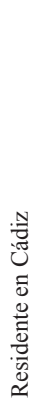 & 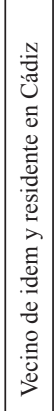 & 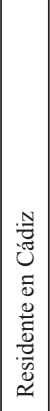 & 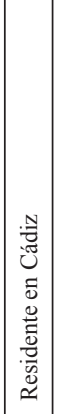 & 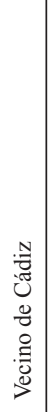 & 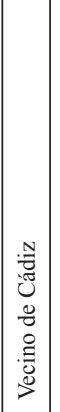 & 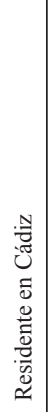 & 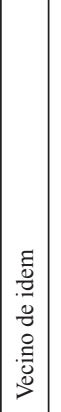 & 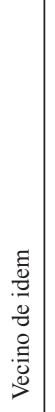 & 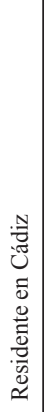 & 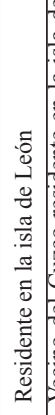 & 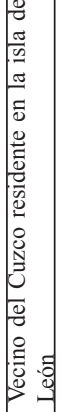 & 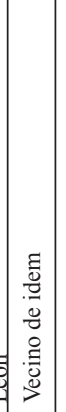 & 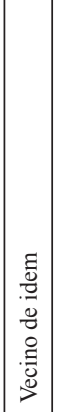 & 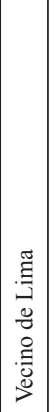 & 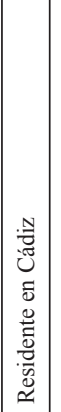 & 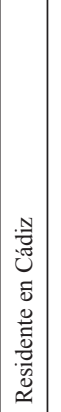 & 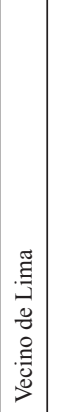 & 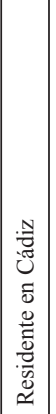 & 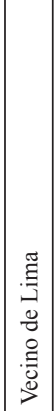 & 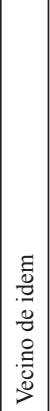 & 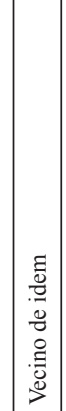 \\
\hline. & 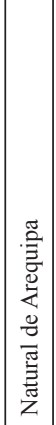 & 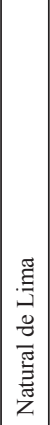 & 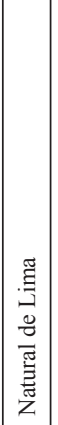 & 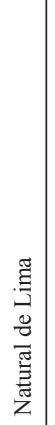 & 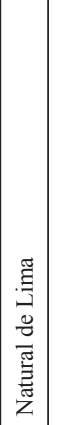 & 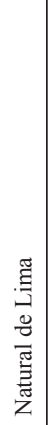 & 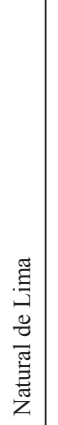 & 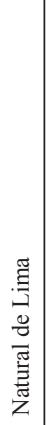 & 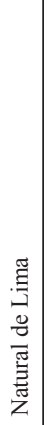 & 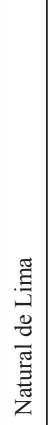 & 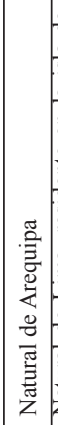 & 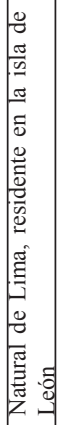 & 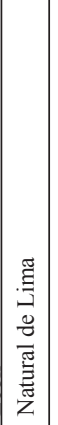 & 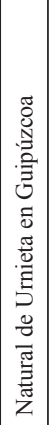 & 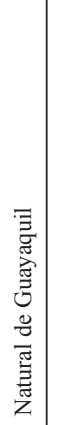 & 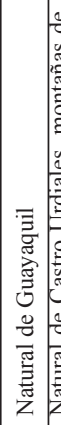 & 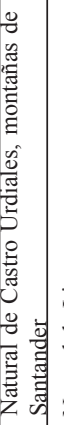 & 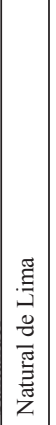 & 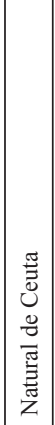 & 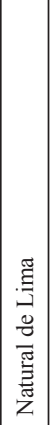 & 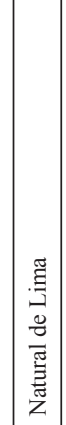 \\
\hline
\end{tabular}

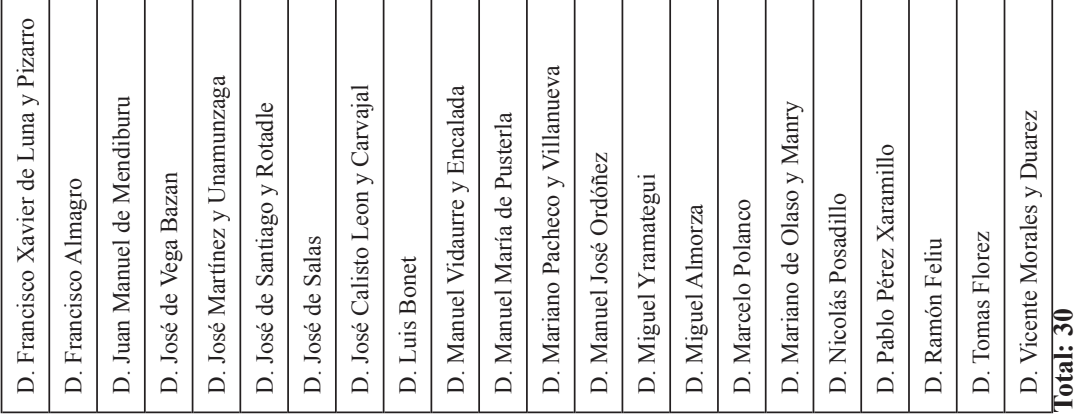




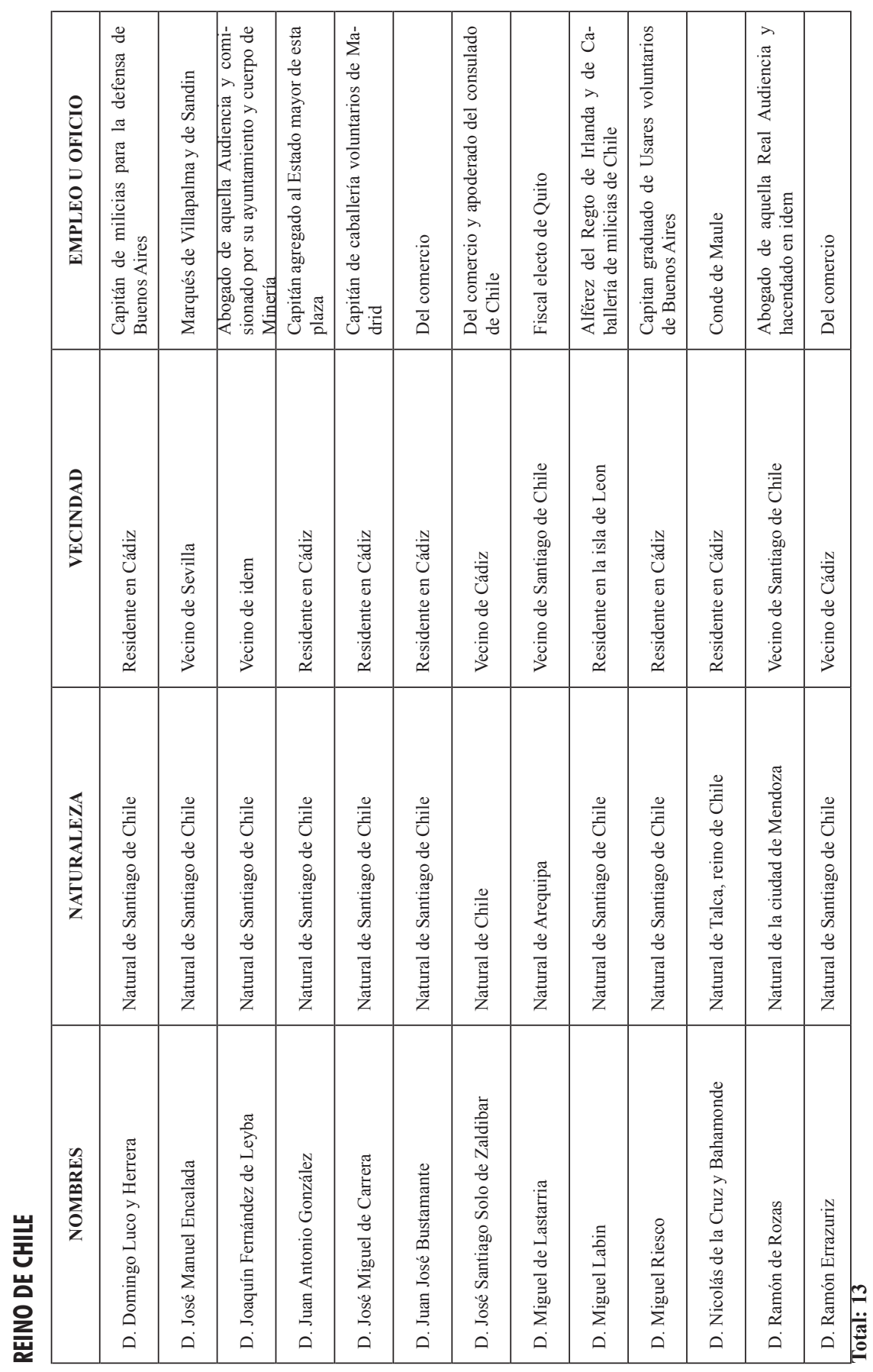




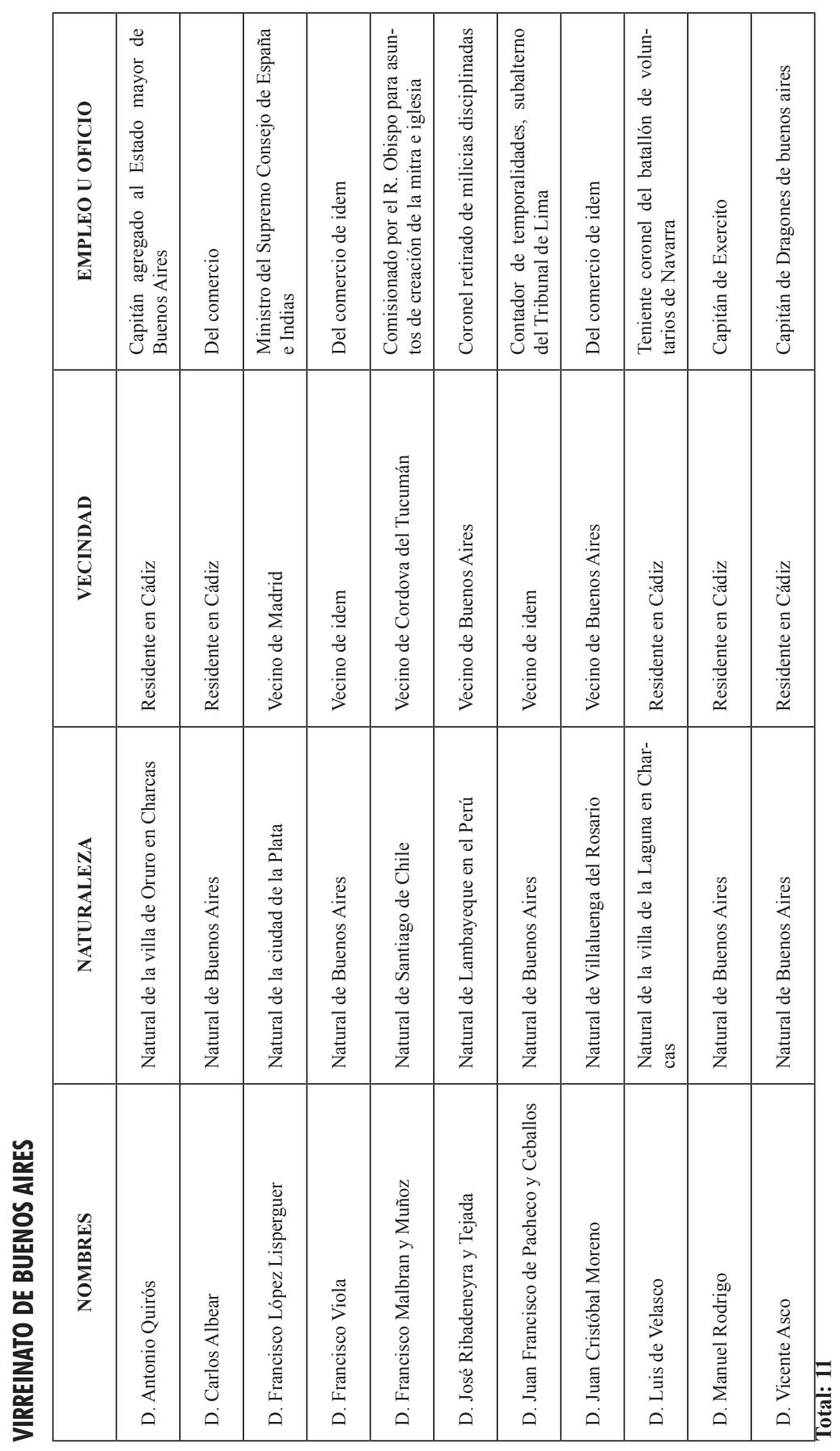




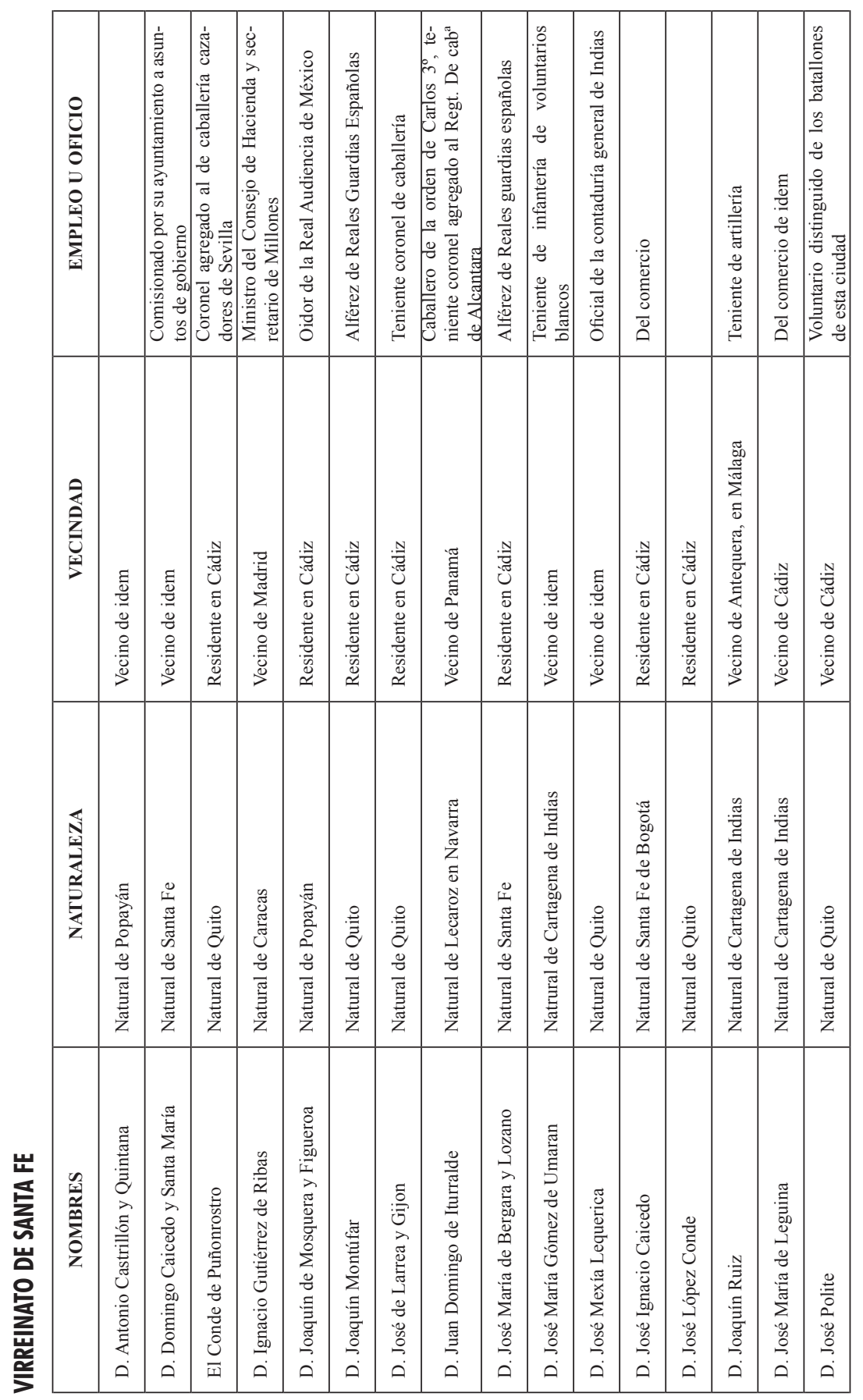



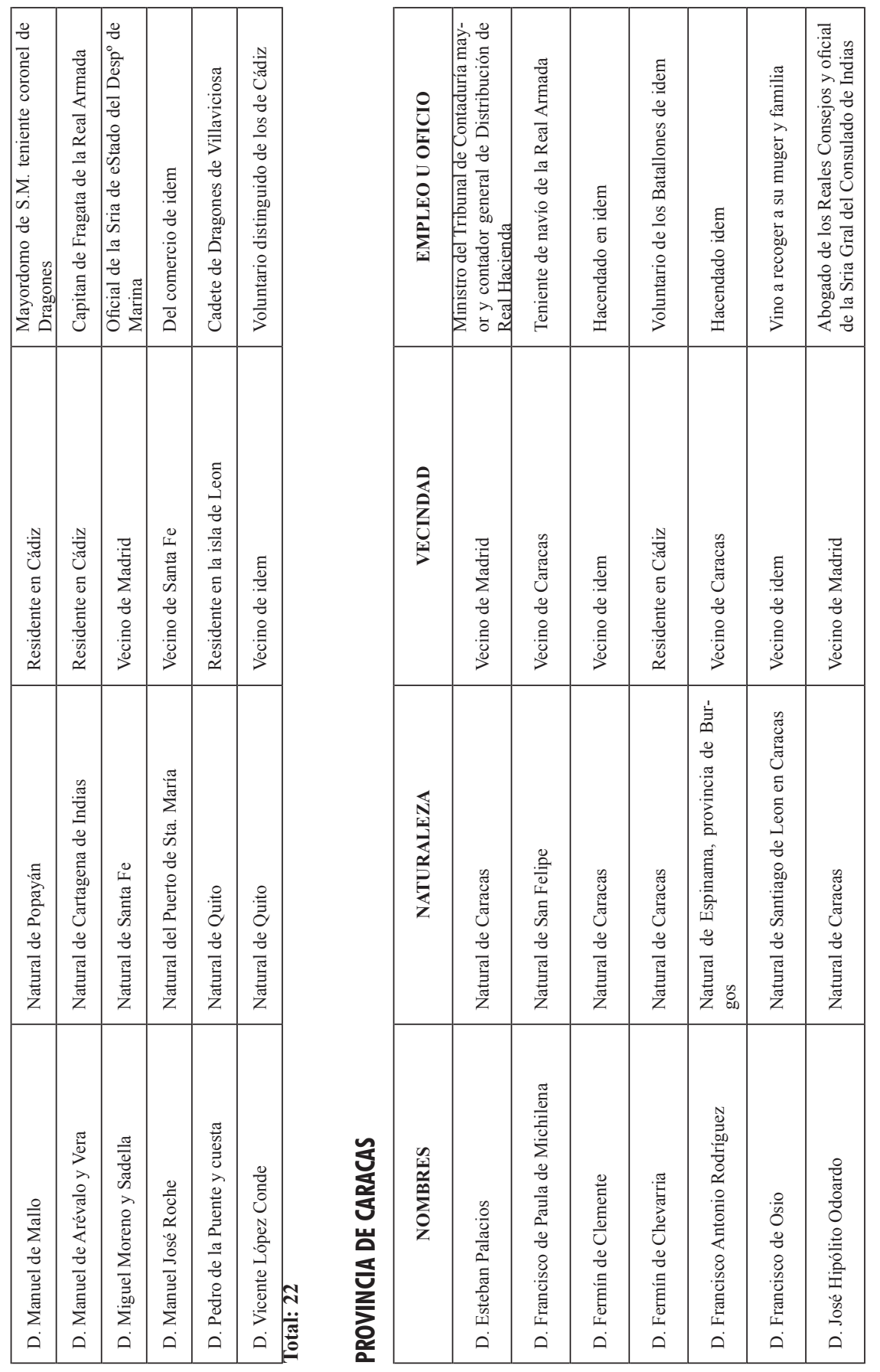


\begin{tabular}{|c|c|c|c|}
\hline 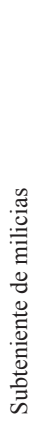 & 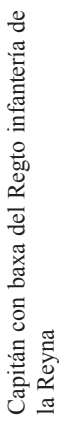 & 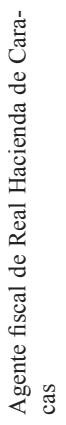 & 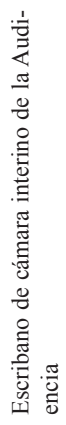 \\
\hline 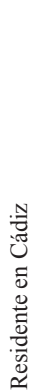 & 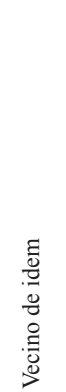 & 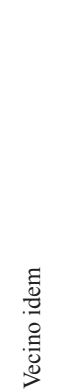 & 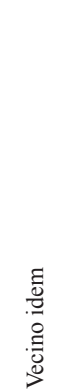 \\
\hline 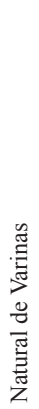 & 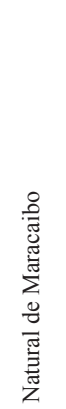 & 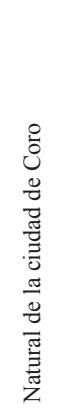 & 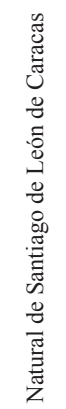 \\
\hline 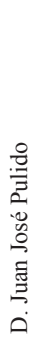 & 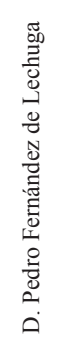 & 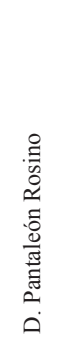 & 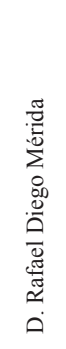 \\
\hline
\end{tabular}


Al listado elaborado añadió Valiente una nota aclaratoria dirigida también a la Regencia en la que reconocía haber incluido en la lista a algunos americanos que no cumplían con el requisito de la edad para ser elegidos diputados. Analizando la lista del consejero y contrastándola con el resto de listados elaborados en las provincias, se deduce que Valiente dejó fuera de la elección a bastantes personas. Rieu Millan apunta la hipótesis de que el requisito de alfabetización exigido por el consejero al solicitar que se presentasen los nombres por escrito, fuera la causa de la exclusión de muchos americanos. No podemos descartar esta posibilidad, puesto que desconocemos el criterio que el consejero utilizó para incluir a unos y excluir a otros nombres de la lista.

El listado definitivo, por tanto, con los nombres de entre los que se procedió a la elección final se comprende de la lista de los de Cádiz elaborada por Valiente, 165 americanos, más la lista de Sebastián de Torres de los que estaban en la isla de León, otros doce.

\section{Américas e Islas Filipinas}

Lista de los sujetos respectivos a las Américas e Islas Filipinas que han concurrido en esta isla de León en los días 21, 22 y 23 del corriente ante el Ilmo. Sr. D. Sebastián de Torres ministro del Consejo y Cámara de España e Indias a la presentación de papeletas para la elección de diputados de Cortes por lo perteneciente a dichos dominios.

\section{Isla de Cuba}

D. José de Zayas natural de la Havana mariscal de campo de los Rs. Ejércitos y comandante Gral de la $4^{\text {a }}$ división del Centro.

D. Lorenzo de Villafranca natural de la Havana teniente del Real cuerpo de Artilleria con destino a este Ejército

D. Antonio Villafranca natural de la Havana capitán de infantería y $2^{\circ}$ ayudante mr del 1er batallón de Rs. Guardias Españolas.

D. Jose Barison natural de la Havana segdo. Maestro de la Rl. Esquela de Navegación de id. Departamento. 


\section{Benasuela [Venezuela] en Caracas}

D. Feliciano Montenegro y Colon natural de la ciudad de Caracas del Capn. Del Batallón de Tiradores de Cádiz y vocal del Consejo de Guerra permanentes.

\section{Reino de México}

D. José Maria Conillo Albornoz natural de la ciudad de Antequera de Oaxaca Reino de México Comandante del 3er Batallón del Regimiento Infant ${ }^{a}$ de ordenes Militares.

\section{Buenos Aires}

D. José Olaguer Filire natural de Montevideo capitán del Regimiento de ords. Militares.

D. Juan Zufriategui natural de Montevideo ayudante de Usares de id.

D. Angel Sanchez de Sotoca natural de Buenos Aires capitan con funciones de sargento mr. Del Regimiento de Cav a de Farnesio.

\section{Reino del Perú}

D. Manuel Villanueva y Viague natural de la ciudad de Lima Capn. De la $4^{\mathrm{a}}$ compa del 1er Batallón de Rs. Guardias Españolas.

D. Ramon Nieto Polo natural de la ciudad de Cuenca en el Perú capitán de Rs. Guards. Españolas Brigadier y comandante Gral. De la $2^{\mathrm{a}}$ sesión de la $4^{\mathrm{a}}$ División de este Ejército.

\section{Islas Filipinas}

D. Pedro Perez de Tagle natural de la ciudad de Manila capitán de las Islas Filipinas 1er teniente de la $4^{\mathrm{a}} \mathrm{Comp}^{\mathrm{a}}$ del $2^{\circ}$ Batallón de Rs. Guardias Españolas.

Cuyos interesados bajo de su firma manifestaron residir en esta Isla ser mayores de 25 años y no comprenderle ninguna de las excepciones legales.

Real Isla de León 24 de agosto de $1810^{30}$.

${ }^{30}$ ACDM, Serie General, leg. 124, no 35. 
Esto es, en definitiva la elección tuvo lugar entre un total de 177 electores $^{31}$.

\section{La elección definitiva}

Así las cosas, como hemos indicado, la lista definitiva elaborada por José Pablo Valiente fue remitida a la Regencia con fecha de 23 de agosto de 1810. Ante la dilación de la reunión de las Cortes y las presiones que recibía la Regencia para que la ejecutara, se decidió que se abrieran cuando estuvieran reunidos la mitad más uno de los diputados que debían componerlas, cuyo cálculo se había cifrado en 285. La noche del 8 de septiembre, José Pablo Valiente se presentó ante los regentes para comunicar la instrucción que había formado para la elección de los americanos y de los peninsulares procedentes de provincias ocupadas. El resultado de sus cómputos suponía que se debían elegir 30 americanos - como ya había indicado anteriormente- y 23 peninsulares. La Regencia emitió entonces un decreto fijando el número de diputados suplentes por América y las provincias ocupadas y dictando reglas para esta elección. Las calidades para ser elegido diputado eran las mismas tanto para los propietarios como para los suplentes e igualmente para los peninsulares que para los americanos. Sin embargo, y tal vez previniendo futuras reclamaciones, la Regencia aclaraba que la elección de suplentes se dirigía principalmente a salvar la unión general de los territorios americanos con su metrópoli, y por si acaso, puntualizaba que no se trataba de que hubiera mayor o menor número de estos diputados sino de que concurrieran a la elección para que la representación fuera completa, según una cuestión de conveniencia y necesidad. Asimismo, se repartía un diputado suplente por cada una de las provincias peninsulares ocupadas, cuyos naturales debían presentarse para votar ante el ministro del Consejo designado para cada una de ellas ${ }^{32}$. Para concurrir a la elección debía haber un número de electores

\footnotetext{
${ }^{31}$ En el legajo 124, $\mathrm{n}^{\circ} 23$ de la Serie General de Expedientes del Archivo del Congreso aparece una lista con el número de emigrados de las provincias ocupadas por los franceses en la península. Al pie de ese listado, en una nota dice brevemente: "vecinos de las diferentes provincias de América: 176”. El que falta es Ramón Power, que como ya está en Cádiz y es considerado propietario, no está incluido en la elección de los suplentes.

${ }^{32}$ Ante el decano del Consejo, Josef Colón debían votar los de Ávila, Madrid, Segovia y Toledo; ante Manuel de Lardizábal los de Álava, Aragón Guipúzcoa, Navarra, Soria y Vizcaya con sus encartaciones; ante Bernardo de Riega los de Córdoba, Granada, Jaén, La Mancha y Sevilla y ante el conde del Pinar los de Asturias, Burgos, León, Palencia, Salamanca, Toro, Valladolid y Zamora. Para un estudio de estas elecciones en territorio peninsular véase CHAVARRI SIDERA, Pilar. Las elecciones de diputados a las Cortes generales y extraordinarias (181-1813), Centro
} 
de primer grado al menos de veintiuno. Éstos, nombrarían a siete electores, los de mayor voto, quienes en una segunda elección, a su vez designarían a los tres candidatos definitivos. De entre estos tres nombres se extraería por suerte el diputado para las Cortes.

El mismo sistema de elección se seguiría para los americanos. El artículo dieciocho del decreto establecía que en el caso de que por una provincia no se reunieran al menos los veintiún electores determinados, éstos se juntarían con otra para conseguir el número. Sin embargo, y debido al corto número de naturales que existían en el territorio, en la segunda elección, en lugar de tres electores se elegirían dos, de entre los que se sortearía al diputado correspondiente.

Pocos días después, el 13 de septiembre, la Regencia llamaba a cinco diputados de los elegidos en propiedad en sus provincias para examinar sus poderes y proceder a la elección de una comisión para que se encargara de revisar los de los diputados que fueran llegando. Finalmente, el 15 de septiembre se publicaba el decreto que fijaba la apertura de las Cortes para el día 24 del mismo mes.

Respecto al momento exacto de la elección de los suplentes americanos, los días 15 y 16 de septiembre procedió el ministro del Consejo Sebastián de Torres a recoger los votos y listas emitidos en la isla de León, encargo que había establecido la Regencia en el decreto del día 8 . Una vez realizada la elección en la isla se remitió el acta a Cádiz donde en el momento de la elección se computaron a cada provincia los que correspondían a medida que se iban nombrando los siete electores que después habrían de proponer los dos nombres para ser diputados. Las elecciones se verificaron los días 20, 21 y 22 de septiembre en Cádiz bajo la presidencia de José Pablo Valiente, como indica el acta. En primer lugar, se leían los nombres, naturaleza, vecindad y profesión de los presentados por cada provincia y se procedía a la elección de los siete electores. El resultado se publicaba inmediatamente si no había ninguna reclamación. Seguidamente estos siete electores se retiraban a una habitación donde proponían el doble de número de electores que el de diputados señalados por provincia, éstos se iban sorteando de dos en dos y colocándose separadamente en dos vasijas. El acto se realizaba de la siguiente manera: "se escribía el nombre de cada uno en su papeleta respectiva y colocadas luego cada una de por sí en diferente vasija, un niño sacaba una de aquellas, y después de leída en alta voz, era proclamado

de Estudios Constitucionales, Madrid, 1988. 
Diputado aquel cuyo nombre acababa de leerse" ${ }^{\text {"33 }}$. Después, volvían a retirarse los siete electores y realizaban la misma operación tantas veces fuera necesaria para completar el número de diputados correspondiente a cada provincia. Terminado el acto, se extendían inmediatamente los poderes que eran firmados por los siete electores y autorizados por el escribano de Cámara.

En la lista definitiva de diputados suplentes americanos elegidos bajo este sistema sólo aparecen veintinueve nombres, ya que el diputado por Puerto Rico, como se dijo anteriormente, ya se hallaba en Cádiz y no fue necesaria su elección ${ }^{34}$. El listado fue el siguiente.

Noticia de la elección de los S.S. Diputados suplentes de las dos Américas, e Islas Filipinas, hecha conforme al R1. Decreto de 8 del corriente en Junta celebrada en la Capilla de la Orden $3^{\text {a }}$ del Convento de los R.R.P.P. Descalzos, baxo la Presidencia del Ilmo. S. D. José Pablo Valiente Ministro del Supremo Consejo y Cámara de España e Indias y por ante el Essno. De Cámara D. Pedro de Montes y Orihuela en los días 20, 21 y $22^{35}$.

\footnotetext{
${ }^{33}$ FERNÁNDEZ MARTÍN, Manuel. Derecho parlamentario, t. 1, p. 700.

${ }^{34}$ Inexplicablemente M. Teresa Berruezo insiste en que el número de suplentes americanos era de 28 y el de peninsulares de 65 cuando el decreto establece claramente la cifra de 30 y 23 respectivamente. Cifras que quedan demostradas con la documentación aportada en este trabajo y en el Pilar Chavarri para el caso peninsular.

${ }^{35}$ ACDM, leg. $124, n^{\circ} 35$.
} 


\begin{tabular}{|c|c|c|c|}
\hline $\begin{array}{l}0 \\
2 \\
z \\
0 \\
0 \\
0 \\
0 \\
0 \\
0\end{array}$ & 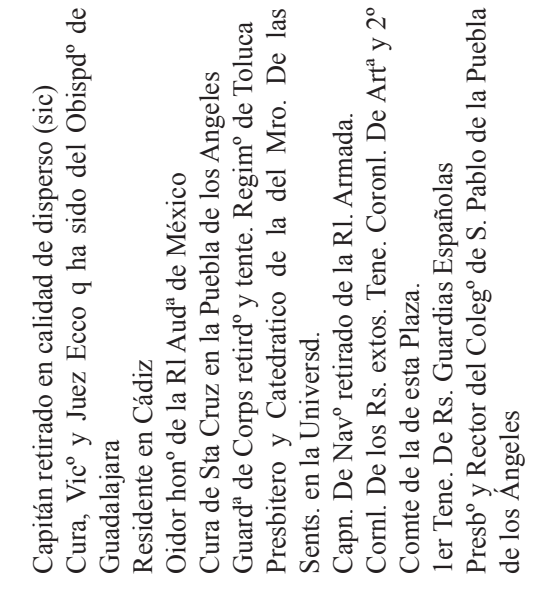 & 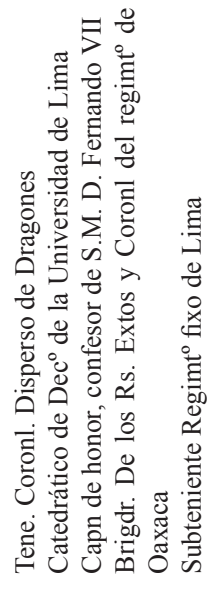 & 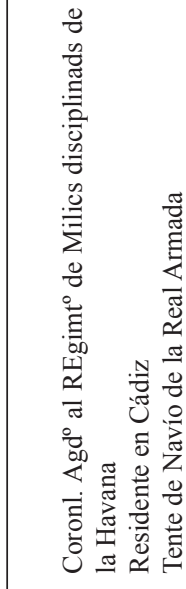 \\
\hline 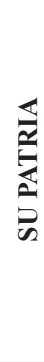 & 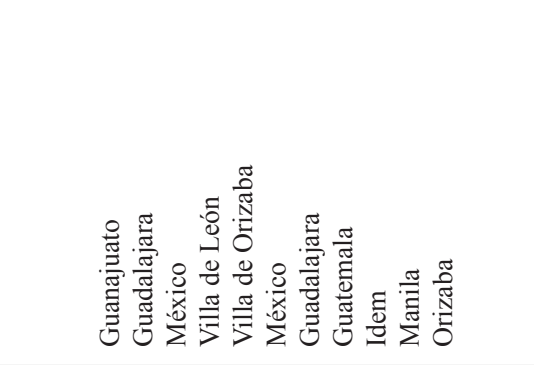 & 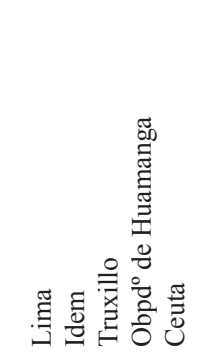 & 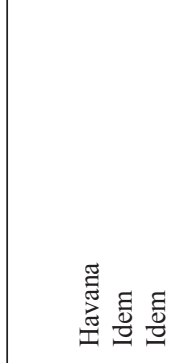 \\
\hline 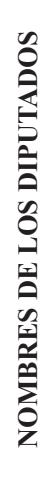 & 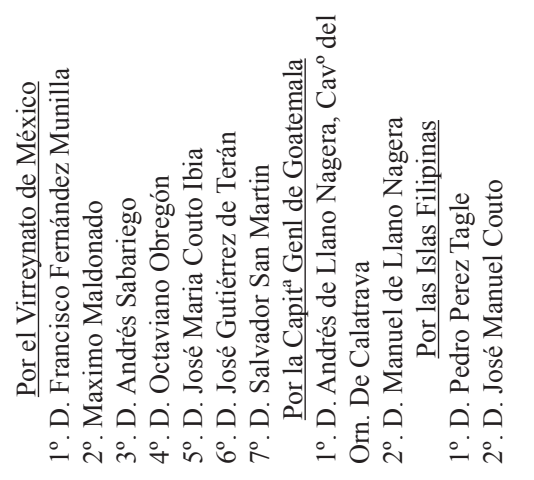 & 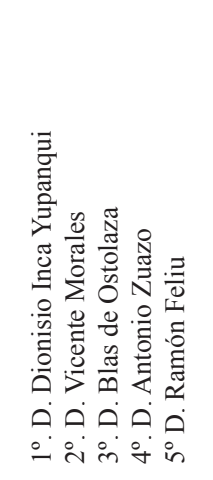 & 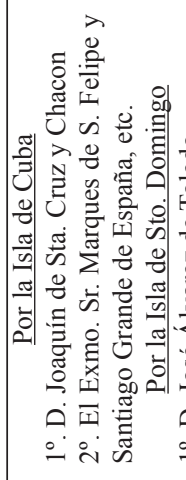 \\
\hline $\begin{array}{l}\sum^{2} \\
\text { z } \\
0 \\
0 \\
\frac{1}{2}\end{array}$ & 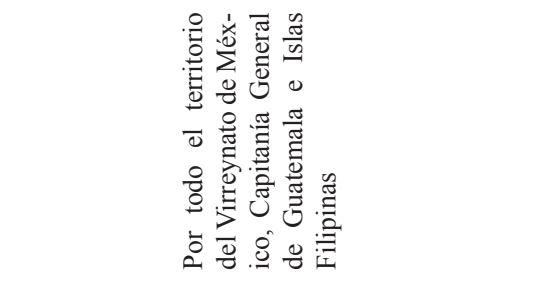 & 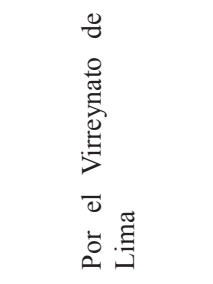 & 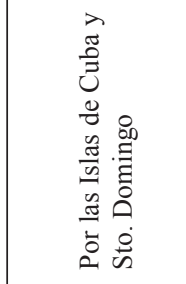 \\
\hline
\end{tabular}




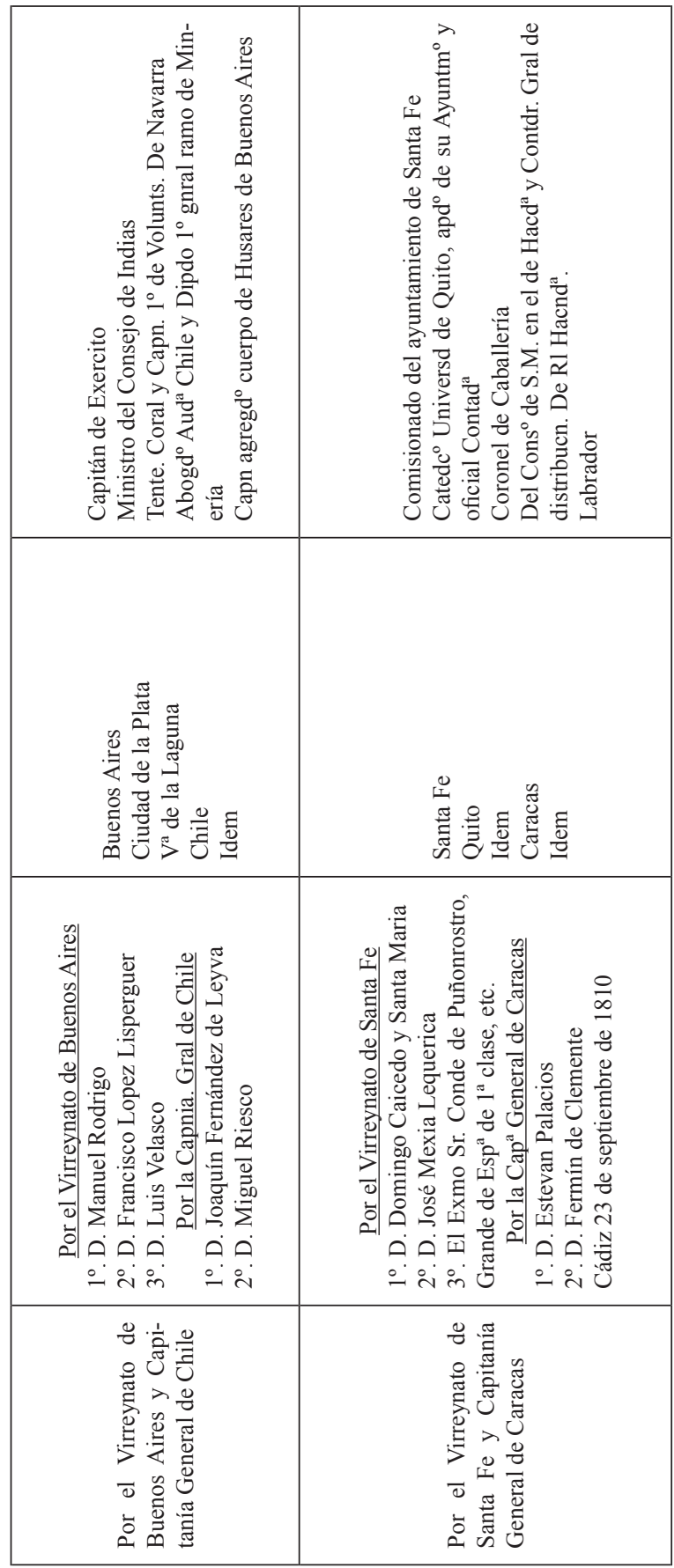


Como vemos, en la elección se siguió estrictamente lo decretado por la Regencia en cuanto a número de diputados y reunión de las provincias que no tuvieran suficientes electores con las inmediatas. Y también, respecto a que sólo concurrieran los americanos que se encontraban en Cádiz y en la isla de León. La documentación trabajada demuestra que el número de americanos entre los que se realizó la elección de diputados suplentes fue exactamente de 177. Un número bastante corto para representar a toda la América, efectivamente, pero también las circunstancias del momento hacían difícil otro tipo de elección. También es cierto que estos pocos americanos representaban a una parte exclusiva de la población, criollos comerciantes, funcionarios o militares, y que las "clases populares", indios y mestizos no estaban presentes en las elecciones, pero no creo que se pueda utilizar como argumento distintivo de América, pues para el resto de la península tampoco podemos decir que estuvieran presentes las capas sociales más populares. Otra cosa sería plantear si estos representantes realmente se consideraban como las voces de los que no podían estar presentes. Vistos los posteriores debates parlamentarios parece que así era, sobre todo entre aquellos de ideas liberales, claro está. Sin embargo, sí es excepcional que en la monarquía española los territorios ultramarinos coloniales tuvieran por primera vez representación en los órganos institucionales de la misma. También la portuguesa sería ejemplo de esto. Pero ni la monarquía británica ni la francesa habían dado este paso antes, a pesar de que sus revoluciones se hayan convertido en el paradigma a seguir. Tal vez, precisamente por eso.

\section{Bibliografia}

ARRIAZU, Ma Isabel. La consulta de la Junta Central al país sobre Cortes. Pamplona: Universidad de Navarra, s.d.

ARTOLA, Miguel. Los orígenes de la España contemporánea. Madri: Instituto de Estudios Políticos, 2 v., 1975.

ARTOLA, Miguel.. La España de Fernando VII, Historia de España de Ramón Menéndez Pidal. Madrid: Espasa Calpe, XXXII, 1976.

ARTOLA, Miguel.. La guerra de independencia. Madri: Espasa, 2007.

AYMES, J. R.. La guerra de independencia en España (1808-1814). Madri: Siglo XXI, 1986.

BERRUEZO LEÓN, María Teresa. La participación americana en las Cortes de Cádiz, (1810-1814). Madri: Centro de Estudios Constitucionales, 1986.

CASTEL, Jorge. La Junta Central Suprema y Gubernativa de España e Indias. Su creación, organización y funcionamiento. Madri: Marto, 1950. 
CHÁVARRI SIDERA, Pilar. Las elecciones de diputados a las Cortes generales y extraordinarias (181-1813). Madri: Centro de Estudios Constitucionales, 1988.

CHUST, Manuel. La cuestión nacional americana en las Cortes de Cádiz. Valencia: Fundación Instituto Historia Social-unED-UnAM, 1999.

CHUST, Manuel (ed.). 1808. La eclosión juntera en el mundo hispano. México: FCE, 2007.

COLÓN, José Joaquín. España vindicada en sus clases y autoridades de las falsas opiniones que se le atribuyeron. Madri: 1814.

ESDAILE, Charles. España contra Napoleón. Guerrillas, bandoleros y el mito del pueblo en armas (1808-1814). Barcelona: Crítica, 2006.

FERNÁNDEZ MARTÍN, Manuel. Derecho parlamentario español. Madri: Publicaciones del Congreso de los diputados, 2 t., 1992.

FONTANA, Josep. La crisis del Antiguo Régimen, 1808-1833. Barcelona: Ariel, 1971.

GENOVÉS AMORÓS, Vicent. València contra Napoleó. Valencia: L’Estel, 1967.

HERNANDO SERRA, María Pilar. El ayuntamiento de Valencia y la invasión napoleónica. Valencia: Publicaciones de la Universitat, 2004.

LA PARRA, Emilio, Manuel Godoy. La aventura del poder. Barcelona: Ed. Tusquets, 2002.

LARDIZÁBAL, Miguel de. Manifiesto que presenta a la nación el consejero de Estado don Miguel de Lardizábal y Uribe, uno de los cinco que compusieron el Supremo Consejo de Regencia de España e Indias, sobre su conducta política en la noche del 24 de septiembre de 1810, Alicante, 1811.

LOVETT, Gabriel H. La guerra de la independencia y el nacimiento de la España contemporánea, Barcelona: Península, 2 v., 1975.

MANIFIESTO fijando los dias en que se han de convocar y celebrar las Cortes generales de la monarquía española, fecha 28 de octubre de 1809.

MOLINER, Antonio, Revolución burguesa y movimiento juntero en España. Lleida: Milenio, 1997.

PUYOL MONTERO, José María. "La creación del Consejo y Tribunal Supremo de España e Indias (Consejo reunido), por la Junta Central en 1809”. Cuadernos de Historia del Derecho, no 12, 1995, p. 189-236.

QUINTERO, Inés. "Las juntas de Caracas” In CHUST, Manuel (ed.). 1808. La eclosión juntera en el mundo hispano. México: FCE, 2007, p. 334-355.

RIEU MILLAN, Marie Laure. "La suppleance des deputes d'outre-mer aux Cortes de Cadix. Une laborieuse preparation". Melanges de la Casa de Velázquez, t. XVII, 1987, p. 263-289.

RIEU MILLAN, Marie Laure.. Los diputados americanos en las Cortes de Cádiz. Madri: CSIC, 1990. 
RODRÍGUEZ LÓPEZ-BREA, Carlos M. Don Luis de Borbón. El cardenal de los liberales (1777-1823). Toledo: Junta de Castilla La Mancha, 2002.

ROURA, Lluís. "Guerra y ocupación francesa. ¿Freno o estímulo a la Revolución española?", in CHUST, Manuel e FRASQUET, Ivana (eds.). La trascendencia del liberalismo doceañista en España y en América. Valencia: Biblioteca Valenciana, 2004, p. 13-30.

SÁNCHEZ-ARCILLA BERNAL, José. "El Consejo y Tribunal Supremo de España e Indias (1809-1810). (Notas para su estudio), in La España medieval, t. V. Madrid: Editorial de la Universidad Complutense, 1986, p. 1033-1050.

SUÁREZ, Federico. El proceso de la convocatoria a Cortes (1808-1810). Pamplona: Eunsa, 1982.

Recebido: abril/2008 - Aprovado: setembro/2008 